University of South Florida

DIGITAL COMMONS

@ UNIVERSITY OF SOUTH FLORIDA
Digital Commons @ University of

South Florida

3-1-2002

\title{
Land Developer Participation in Providing for Bus Transit Facilities/Operations
}

CUTR

Follow this and additional works at: https://digitalcommons.usf.edu/cutr_nctr

\section{Scholar Commons Citation}

CUTR, "Land Developer Participation in Providing for Bus Transit Facilities/Operations" (2002). Research Reports. 202.

https://digitalcommons.usf.edu/cutr_nctr/202

This Technical Report is brought to you for free and open access by the National Center for Transit Research (NCTR) Archive (2000-2020) at Digital Commons @ University of South Florida. It has been accepted for inclusion in Research Reports by an authorized administrator of Digital Commons @ University of South Florida. For more information, please contact digitalcommons@usf.edu. 


\title{
LAND DEVELOPER PARTICIPATION IN PROVIDING FOR \\ BUS TRANSIT FACILITIES AND OPERATIONS
}

\author{
Sara J. Hendricks \\ Principal Investigator \\ Cecilia Dyhouse \\ Graduate Student Assistant \\ Center for Urban Transportation Research
}

March 2002 


\section{NCTR}

\section{CENTER FOR URBAN TRANSPORTATION RESEARCH}

University of South Florida

4202 E. Fowler Avenue, CUT 100

Tampa, FL 33620-5375

(813) 974-3120, SunCom 574-3120, Fax (813) 974-5168

Edward Mierzejewski, CUTR Director

Joel Volinski, NCTR Director

Dennis Hinebaugh, Transit Program Director

The contents of this report reflect the views of the author, who is responsible for the facts and the accuracy of the information presented herein. This document is disseminated under the sponsorship of the Department of Transportation, University Research Institute Program, in the interest of information exchange. The U.S. Government assumes no liability for the contents or use thereof. 
TECHNICAL REPORT STANDARD TITLE PAGE

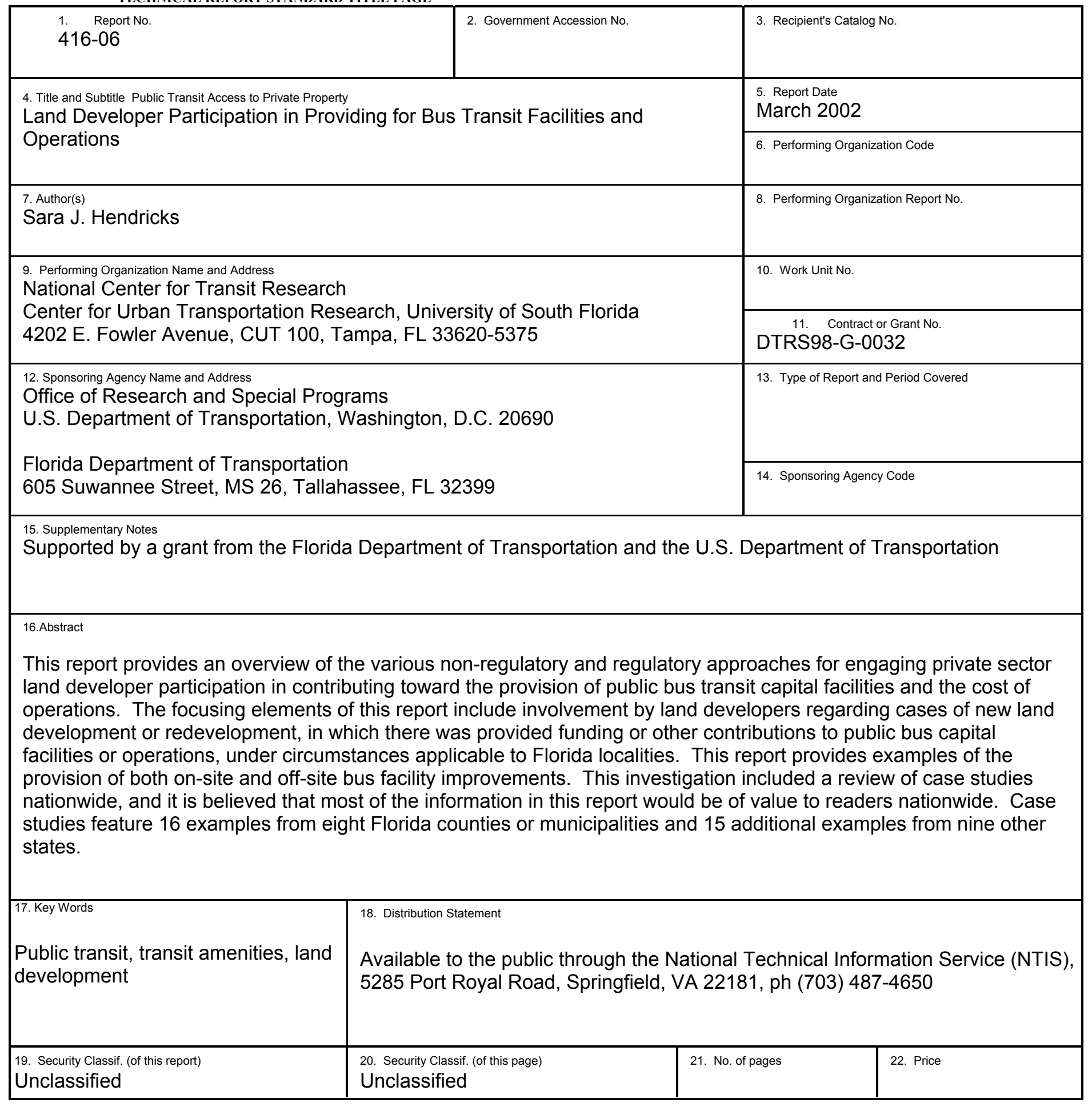




\section{Table of Contents}

Executive Summary ................................................................................... i

Introduction and Purpose of Report...................................................... 1

Method of Study...................................................................................... 3

Legal Foundation for Land Developer Contributions ..................................... 4

Current Approaches for Engaging Private Sector Involvement..................... 9

Non-Regulatory Approaches ..................................................................... 10

Joint Development ............................................................................... 11

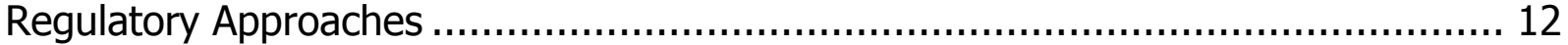

Local Land Development Regulations ...................................................... 14

Tax Increment Financing (TIF) ........................................................... 15

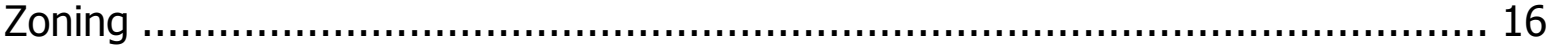

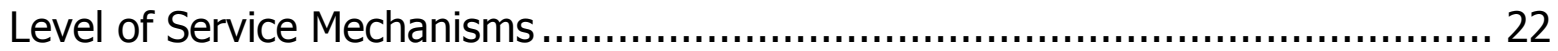

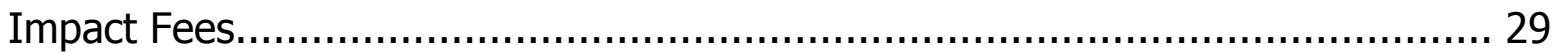

Developments of Regional Impact .......................................................... 35

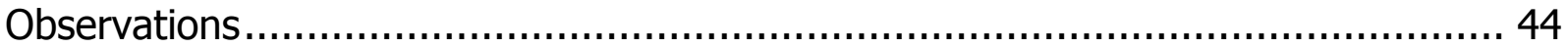

Future Considerations for Interactions with Developers ........................... 46

Non-Regulatory Approaches ...................................................................... 46

Employment Park Foundations .............................................................. 46

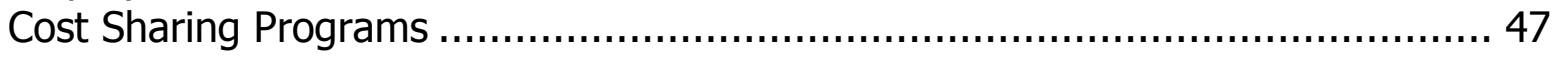

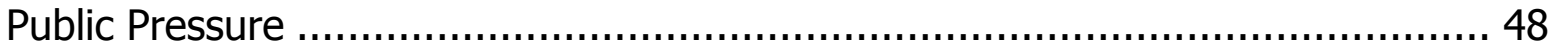

Low Income Housing ......................................................................... 49

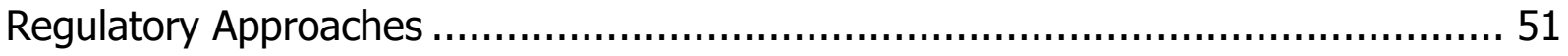

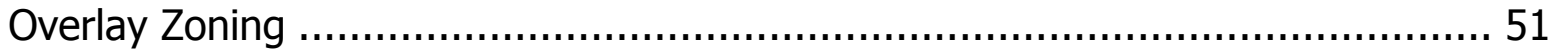

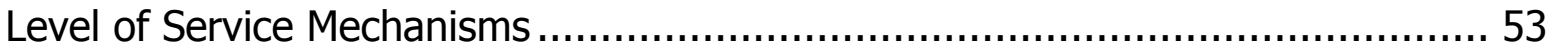

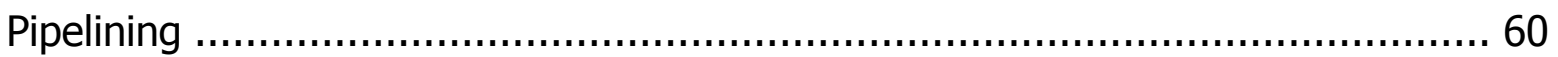

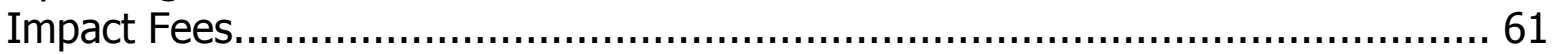

Review Process for Developments of Regional Impact ................................. 62

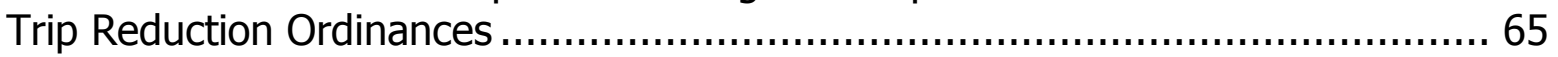

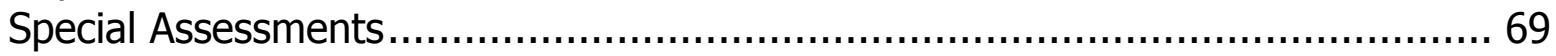

Recommendations ...................................................................................... 73

Appendix A Port Orange Comprehensive Plan.............................................. 1

Appendix B Literature Review ................................................................ 1 


\section{Executive Summary}

\section{Introduction}

This report provides an overview of the various non-regulatory and regulatory approaches for engaging private sector land developer participation in contributing toward the provision of public bus transit capital facilities and operations. It provides information from around the country but focuses on circumstances applicable to Florida localities.

This study specifically examined the development of bus transit facilities and services because far more transit systems are exclusively bus transit systems and those that do run rail service usually operate bus service as well.

The report first presents information about those mechanisms used currently in Florida localities. The report then presents information on other mechanisms not currently known to be used in Florida, but which are allowable under Florida law and have potential to provide additional funds for public bus transit capital and operations.

The funding needs of bus transit systems include capital expenses such as buses and shelters. Capital needs also exist for accessibility features at bus stops, such as sidewalks, adequate right-of-way, curb cuts and pull-out bays; passenger amenities; bus stop signage; and park and ride lots. Operating expenses constitute the most serious funding gap, and private sector contributions for operations, outside a special district, have been infrequent at best.

Provided herein are examples of the provision of both on-site and off-site bus facility improvements. This investigation included a review of case studies nationwide. It is believed that most of the information presented would be of value to readers nationwide, though most of the recommendations are placed in the context of Florida. Case studies include 16 examples from eight Florida counties or municipalities and 15 additional examples from nine other states.

\section{Comprehensive Planning and Regulatory Processes}

Local government planning and regulatory processes provide the framework for empowering local governments and transit agencies to engage private sector land developers to contribute toward the costs of public bus transit service and capital facilities. These processes include the transit development planning process, the local government comprehensive planning process and the requirements contained in the land development code. 
The land development code is the set of regulatory tools that establishes what is required of private land developers before building approvals are granted. A strong land development code starts with a well-crafted local government comprehensive plan (LGCP). The LGCP should provide policies that prioritize transit-friendly land development patterns. It is important that the LGCP strongly and clearly provide the policy foundation for transit development as a part of the land development process, otherwise the implementing ordinances will lack effectiveness. Ideally, the LGCP and the transit development plan (TDP) should support and reinforce each other so that land development and redevelopment occur where public bus transit is able to efficiently provide high quality service.

The adoption of an urban service boundary by a host local government is an important first step toward containing and directing growth, and improving the efficiency of public services delivery. However, because the transit service area does not often extend either to the entirety of the transit taxing district or to the limits of an urban services boundary, it can be very effective for the host local government to designate transit service corridors. Transit service corridors are areas along roadways that are served by existing and proposed bus routes. In these corridors, the city ensures adequate roadway level of service (LOS) and encourages site developments that support transit. Furthermore, the city requires on-site access for a bus stop and the incorporation of transit-friendly design, and commits the city to provide improvements to existing bus stops.

Predicated upon an LGCP with clear policies, the land development code (LDC) should be kept up-to-date to implement the LGCP. The best LDCs are a balance between providing predictability regarding what is expected of private land development and providing flexibility to enable the best and most appropriate transit improvements. A good LDC also provides the right balance between stipulating enough requirements to help develop good transit service (which ultimately proves itself as an enhancement to development), without being so onerous as to drive land development out of the area.

\section{Regulatory Approaches}

\section{Zoning}

This report discusses three different types of zoning: conditional, incentive and overlay, which can facilitate land developer participation. Conditional and incentive zoning are presented with existing examples of their use to secure bus transit facilities. The State of Virginia provides examples of the use of conditional zoning in densely populated counties to support transit. The approach is to require developers to abide by transportation management plans that spell out numerous provisions for public transit. 
This may provide ideas for local governments as Florida communities continue to urbanize and rely more on transit, as well as for developments of regional impact.

Overlay zoning is presented as a future consideration for local governments to apply as a transit overlay zone for bus rapid transit. It also may work well for larger, permanent bus facilities where higher density is encouraged for attracting and facilitating land development. Transit overlay zones may simplify the development regulatory process for getting zoning approvals for transit facilities, such as park-and-ride lots.

In Orlando, LYNX is an example of a transit agency that does not rely simply on land development regulations, but provides a Mobility Design Manual and a Customer Amenities Manual, which provide explicit and detailed information to the local government and to the land developer regarding what is desired rather than what is required. The development of these manuals recognizes that the transit agency probably will not get what it wants if it does not ask.

\section{Level of Service Mechanisms}

The report also addresses the use of transportation concurrency, as practiced in Florida, as a means to require the provision of transit improvements to maintain adequate standards for transportation level of service. This study has found that transportation concurrency has almost exclusively been applied to mean roadway concurrency. With the exception of Orlando, service standards for public bus transit are generally not framed within the passenger's perspective. Most commonly, local governments have requirements in their land development codes that ensure that land development design provides access to transit, such as walkways, signage and shelters.

However, when the developer cannot demonstrate that roadway improvements will restore and maintain roadway concurrency, arrangements have been worked out for the provision of operating funds. These funds allow localities, such as Hillsborough and Broward counties, to extend bus routes or provide shuttles that connect to regular fixed-route bus service. Generally, the emphasis upon transit improvements is their application as a means to restore roadway level of service, rather than as a means to enhance overall mobility.

Transportation concurrency exception areas have been applied in Gainesville and in Miami-Dade County to secure public bus transit facilities. In Gainesville, the City provides specified standards for bus amenities and capital improvements that the land developer must meet according to development size and impact of the project. In Miami-Dade County, the land development code expressly calls for bus terminals to serve multiple routes. 
There are some promising aspects to the future application of the transportation concurrency law to engage private sector land developer participation in contributing toward public bus facilities and operations. The 1999 legislative changes to transportation concurrency law provided for the allowable use of multi-modal LOS measures. These measures have been newly developed and issued through the Florida Department of Transportation (FDOT). FDOT discourages the application of these multi-modal LOS measures to quantify the value of trade-offs among different modes of travel; however, ongoing research to further refine these measures aims to enable local governments to quantify such trade-offs.

Once local governments are able to incorporate multi-modal LOS techniques into transportation planning activities, then they will have the ability to establish acceptable LOS standards for transit service for locations to satisfy concurrency. Once those standards are established, the basis for requesting the provision of transit facilities and/or operations funding as a part of the land development negotiation process can be established.

The primary need of transit passengers is bus transit availability to serve their travel needs, according to the Transit Capacity and Quality of Service Manual, prepared by Kittelson \& Associates. Transit service must be available before there can be any discussion of transit service quality, as provided by transit facilities and amenities. As a result, the most important bus transit service elements include funding for bus operations to and from the development site. The emphasis of engaging private sector land developer participation should be on funding the primary service measures of availability first, such as frequency of bus service.

In a separate effort to assure transit service availability, Broward County has proposed a transit-oriented concurrency system. The proposal calls for the County to be divided into Transportation Concurrency Management Areas (TCMAs). Each TCMA could either use the new transit-oriented system or opt out of the program and use a conventional concurrency system. A developer pays a fee into the Transit TCMA proportionate to the transportation impact of the proposed development, which would contribute to the funding of the five-year transit development plan.

This proposed assessment, to satisfy transit-based concurrency, is envisioned as a "payand-go" system, meaning that the developer's only obligation is to pay the appropriate amount to the County. Under a "pay-and-go" system, the payment would be made at the site plan stage, when the specific nature of each development is well defined. This would enable a more accurate calculation of the expected impact of each project and eliminate the need for monitoring and enforcement. 


\section{Impact Fees}

Impact fees also are defined and addressed in this report. There are considerable restrictions on the use of impact fees. As a result, impact fee ordinances generally require greater staff time and expertise to administer. As illustrated by the case of Portland, Oregon's service development charges, a great deal of effort goes into calculating the cost of the transportation improvements attributable to each mode of travel that is generated by a new development. The detailed calculations emphasize fairness as a result of a proven precision in the method.

Impact fees are a regulatory device rather than a taxing mechanism and so must not demonstrate that the fees raise excessive revenues. Impact fees must meet the rules that were established in the Dunedin (1976) court case, as well as rational nexus and rough proportionality tests. The funds raised from impact fees are limited to use within a prescribed geographic area. The fees must be spent within a particular time period. They can neither be used to address existing transportation deficiencies nor can they be used for operations or maintenance costs.

Still, impact fees are an available tool to secure transportation capital funds specifically resulting from land development activities. Broward County is the only Florida county that currently administers an impact fee for transit; however, it applies only to properties that require platting within an urban infill area. These conditions apply to very few land developments. Hillsborough County's impact fee ordinance generates some amount for transit based upon existing mode share. The City of Orlando's roadway impact fee program provides credits to the developer in exchange for providing transit improvements.

The 1999 legislative amendments to concurrency providing for multi-modal transportation districts include the provision that "local governments may reduce impact fees or local access fees for development within multimodal transportation districts based on the reduction of vehicle trips per household or vehicles miles of travel expected from the development pattern planned for the district." The intended effect is to encourage developers to adopt development patterns as promoted by multi-modal transportation districts. While this will not raise funds for transit, it should have the positive effect of putting appropriate land development patterns in place that make bus transit more effective.

Considering this new legislation, there may be a missed opportunity when impact fees are considered only for roadways and no other form of transportation. While there may be a reduction of vehicle trips per household, there will almost certainly still be a need for transportation, in one form or another. Broadening our view toward the development of a "transportation impact fee" might open new opportunities to fund transit using private sector land developer participation. 


\section{Developments of Regional Impact}

Included herein is an examination of the development of regional impact (DRI) process, with respect to its applicability in engaging private sector land developer participation in contributing toward public bus transit facilities and operations. Development orders resulting from the DRI process tend to secure such features as:

- coordination between the land developer and the transit agency

- provision of on-site amenities, per the requirements of the local land development code

- transportation demand management and transportation systems management activities

- new route subsidization in the form of a one-time fee or for a specified period of time

- provision of preferential parking

- transit-friendly design, including sidewalk access

Aside from the coordinated review among agencies, the DRI process itself does not appear to result in anything more than what would have occurred for a development of similar magnitude with no multi-jurisdictional impacts.

In most cases, service provided by the various transit properties in Florida stays within city or county boundaries. In Florida, transit service planning focuses service development where there is likely to be the greatest demand, which is not necessarily where new land development is occurring. As a result, strategic planning for the maintenance and expansion of bus systems may or may not be completely aligned with the pattern of new construction and redevelopment activities of an area, which are controlled by market forces. For example, due to budgetary constraints experienced by public bus transit agencies to support the existing customer base, transit agencies may be justifiably hesitant to spread resources across a larger service area by expanding service to newly developing areas. In this way, there is a critical disconnect between marshalling the transit agency's resources to best serve its mission and harnessing the land development process for transit system development. As a result, transit may be in a weaker position to address multi-jurisdictional travel patterns and impacts.

This study reviewed the site impact analysis process that is used to determine the impact of DRIs upon state transportation facilities. With the attention that continues to be placed on developing and refining methods to measure multi-modal level of service, these new methods should be incorporated into both the Florida Administrative Code 9J-2.045 and the instructions for determining impacts as part of the DRI Application for Development Approval. 
Other hurdles in elevating the use of public transit improvements to address the transportation impacts of DRIs are:

- providing public bus transit improvements that can be demonstrated to specifically benefit the particular DRI contributing funds, and

- demonstrating that those particular transit improvements cause a mode shift to transit.

Transportation improvements, as provided by developers, must meet certain tests as provided by State law. These tests are similar to those provided for impact fees, regardless of whether a local government has adopted an impact fee ordinance or not.

- The transportation need that must be mitigated must be attributable to the proposed development paying for the mitigation.

- The amount of the contribution must correspond to the amount needed to mitigate the impacts from the development.

- The funds must go toward improvements to serve that development.

- Developers of DRIs cannot be required to contribute funds for mitigation unless the host local government has an ordinance in place requiring non-DRIs to mitigate their impacts.

- Developers of DRIs cannot be charged twice to mitigate for the same impacts, as in the case that a local host government charges impact fees.

These requirements pose special difficulties for developers to provide transit improvements as mitigation for the transportation impacts of a DRI. For example, if a high quality bus service is not in place, then it is not possible to reasonably estimate the need for transit service by a new development. That is unless there is a way to measure latent demand for transit service. As a result, a very low number of bus trips is estimated. Consequently, a small amount of money or capital facilities is estimated to pay for bus mode share. Funds must be demonstrated to benefit the development. If there is an impact fee ordinance in place, then funds cannot go toward bus operations. This leaves capital facilities as the only alternative with bus shelters as the likely choice. However, the Transit Capacity and Quality of Service Manual assigns bus shelters as an amenity and not a necessary element of bus service availability. Bus shelters do not accomplish much if bus service is not available.

If funds can go toward operations, it is possible to quantify a cost of bus service to cover bus operations to serve those generated trips only; however, this still would not help if bus service does not yet extend out to the DRI. If bus transit service does not already exist in the area, then it is not possible to pay some incremental bus transit cost. Incremental costs paid by the development must be commensurate with the number of new trips generated by the development. 
It is recommended that there be some means to enable local governments to charge development for bus transit improvements. These include the improvements that do not necessarily serve that development, but that go toward bus service development of routes that may be extended to serve them in the future. The contribution should be consistent with the intent to provide transportation facilities concurrent with the impact of development and to maintain a transportation LOS. It also should be commensurate with the mobility demand generated by the development.

\section{Trip Reduction Ordinances}

Trip reduction ordinances (TRO) primarily enlist the participation of property owners and employers, but they also can target land developers. TROs specify the implementation of transportation management efforts that can include public transit promotion. There is generally no limit to what activities are conducted, as long as those activities produce trip reduction results. TROs may be an additional tool that local governments could use to ensure contributions toward public transit. A survey of trip reduction ordinances nationwide resulted in featuring those TROs in this report that were most explicit about providing for transit facilities and operations. The City of Boca Raton has proposed the adoption of a citywide trip reduction ordinance.

\section{Special Financing Districts}

Another tool that has been rarely used but is allowable in Florida is the use of special assessments. Special assessments are fees charged against property within a geographically defined district to finance specific capital improvements or services. Special assessments are used more to pay for new improvements rather than their replacements, are distinct from independent and dependent special districts as well as tax increment financing districts, and can be used to provide public transportation.

Special assessments provide an alternative to negotiating with developers to secure financing for new improvements. Financing through special assessments avoids some of the legal restrictions on local taxation and borrowing, which may be more politically acceptable to taxpayers than other sources of revenue and can be used in addition to exactions. Special assessments expedite the placement of infrastructure, which lowers long-term costs of construction.

Tax increment financing (TIF) is discussed in this report because TIF districts are rarely established without the commitment of a land developer. Tax increment financing is a method of funding public improvements in an area slated for redevelopment. This is done by capturing, for some period of time, all or a portion of the increased tax revenue that may result if the redevelopment stimulates private investment. The report provides the example of the Downtown Orlando Lymmo. 


\section{Non-Regulatory Approaches}

There are three circumstances under which non-regulatory approaches can be successful.

1. The local government and/or the transit agency, and the private land developer each have something uniquely valuable to offer to the others in the partnership.

An example is provided by VOTRAN, the transit service in Volusia County, Florida. VOTRAN enabled Daytona Beach to maintain required public access to the beaches. VOTRAN also was able to offer its own sources of funds that could supplement those of the private developer and the County for a necessary public facility.

In the case of Tri-Met in Portland, Oregon, the City did not want to rely on federal funding for a light rail extension to the airport because federal involvement would have greatly extended the amount of time to complete the project. Private contributions enabled the City to accomplish the light rail extension quickly without the use of federal funds, which included bus transit centers, park-and-ride lots, and bus bays. Packaging Portland's light rail system as a whole, the locally funded airport light rail extension project was offered as the local match for the future eastern extension of light rail in Portland. Subsequently, the eastern light rail extension received 100 percent federal funding. In return, the City had the power to grant the land developer the right to become the main project contractor and the right to lease a prime parcel of land near the airport to develop a business district.

2. Incentive programs and negotiations do not take the place of a strong land development code. In the presence of land development regulations, the existence of incentive programs signals to the developer that there is some flexibility in the process. Incentives also show that there is the desire on the part of the local government to negotiate to achieve the best outcome, above and beyond the minimum legal requirements.

Incentive programs include density bonuses, lower parking requirements (which also reinforces public transit), expedited permitting, and others.

3. Local government planning and permitting staff have effective negotiating skills. The staff also should understand enough about development financing to recognize what requests are too costly for the developer to accomplish. 
Under the topic of non-regulatory approaches, there is also a discussion of future potential opportunities in low-income housing programs. Private land developers can find affordable housing ventures to be attractive for reasons discussed further in this report. Since many low-income housing occupants are also transit users, land developer provision of transit facilities and services could be of significant value for them as well as for transit agencies. It is recommended that the application process for low-income housing projects be reviewed to determine if it is possible to change the rating scale of amenities to reward developers higher points for providing public bus transit access, capital facilities, and service operations. In this manner, the land developer who promises better transit provisions is the one who is awarded the project.

\section{Conclusions}

This report provides numerous examples of non-regulatory and regulatory tools that could be used to engage private sector land developers to contribute toward public bus transit facilities and services. It is recommended that these tools be considered for use in combination, such as the use of impact fees with special assessments.

One further example of a case in Portland, Oregon, using a non-regulatory approach, emphasizes the importance of public pressure to secure a land developer commitment to fund bus transit improvements. This speaks to the potential power and influence of an educated and well-organized community. This may also point to the value to local governments of using available tools, such as transportation management associations, to help educate citizens about the value of a strong public transit system. In this regard, citizens become advocates.

The local government comprehensive planning process, the land development code, and the use of incentive programs are existing tools to help harness the land development process for transit system development. However, these are no substitutes for a local host government whose professional staff and executive leadership are allies and advocates for public bus transit and are committed to making public bus transit a priority in land development negotiations. 


\section{Introduction and Purpose of Report}

The purpose of this report is to provide an inventory and description of the ways in which private sector land developer participation can be engaged to contribute toward the costs of public bus transit capital facilities and operations expenses. The report is intended to be a resource for local and state governments and transit agencies to learn what other areas have done to secure private sector funding for public bus transit facilities and services. The report focuses on contributions by private land developers for bus capital facilities and/or operations costs as a result of new development or redevelopment of land, with a particular emphasis on mechanisms applicable in Florida.

The investigation emphasizes development activities and mechanisms applicable or transferable to Florida for two reasons. First, 11 public transit systems in the state serve populations residing in counties that rate in the top 100 nationwide for population growth, according to the 2000 Census. Consequently, land development activities are proceeding at a brisk pace, resulting in more opportunities to find examples of private sector land development participation in contributing toward the cost of bus transit capital facilities and operations.

Second, the study found that Florida is among the more progressive states in the nation in regard to providing local governments with the authority and the regulatory tools to secure land developer participation. However, this investigation included a review of case studies nationwide, and most of the information in this report should be of value to readers nationwide.

The report focuses upon private land developer participation because the development community is in a position to develop property in a way that does not prevent people from using transit. Ideally, developers also espouse the concept of transit-oriented development, to develop land in such as way that maximizes people's mobility while adding benefits.

The report also focuses upon private land developer participation because not enough public funding is provided to support public transit systems. While local governments in Florida have ample taxing powers, it is generally a political reality that local government leaders impose increased taxes as a last resort. As a result of these circumstances, the study explores other funding sources besides taxation, particularly focusing upon regulatory and non-regulatory approaches to engage private sector land developer participation.

In addition to the participation of land developers, there are a few illustrations in this report featuring the participation of owner/managers of large private developments. These illustrations were included because these entities may also have the power and 
the goal to further develop these substantial properties in the future. In one case, a public university was featured as a contributor because many universities (both public and private) in Florida and nationwide are expanding their campuses to accommodate growing student bodies and are engaged in the business of developing campus facilities. University students are a prime market for transit patronage. Public university funds come from a different revenue stream than that which provides for public transit and so the benefit to transit is similar as if it came from private sector land developer participation.

This report features development examples that include such existing mechanisms as joint development, zoning, concurrency, impact fees and developments of regional impact. A later section discusses future considerations for interactions between local transit providers and land developers, featuring examples of mechanisms not currently used in Florida but that could be used in the future. These include employment park foundations, trip reduction ordinances, and new processes under development relating to transportation concurrency, among others.

Many of the development examples highlighted in this report could actually fit under one or more categories listed. The organization of the development examples is based upon which mechanism appeared to be the key or pivotal element of the development arrangement. For example, if a development is highlighted under the Development of Regional Impact category in this report, it is because the private sector contribution to bus transit was determined by the DRI process itself and not a local government land development code criterion or some other factor.

The study focuses primarily on how funds can be raised by private land developers for bus transit, through the land development or redevelopment process. Much of the focus nationwide upon private sector land developer involvement has been on joint development of land adjacent to light rail stations. This is often referred to as transitoriented development. This study specifically examines the development of bus transit facilities and services because far more transit systems are exclusively bus transit systems, and those that do run light rail service usually operate bus service as well.

Bus transit capital needs primarily include buses, shelters, accessibility features at bus stops, such as sidewalks, adequate right-of-way, curb cuts and pull-out bays, passenger amenities, bus stop signage and park and ride lots. However, operating expenses are the most serious funding issues, and private sector contributions for operations, outside a special district, have been infrequent at best.

This report provides examples of the provision of both on-site and off-site bus facility improvements. Case studies feature 16 examples from 8 Florida counties or municipalities and 15 additional examples from 9 other states. 


\section{Method of Study}

The study includes a literature review of transportation planning texts, journals, transit periodicals, TRIS (Transportation Research Information Services) and other sources related to developer participation in providing bus transit facilities or operations. An annotated bibliography is provided in Appendix B of this report. A search also was conducted by the Planning Advisory Service of the American Planning Association. The Florida Statutes and local codes included in the files of the Municipal Code Corporation were reviewed. Internet searches of federal, state, local and municipal governments web sites were conducted. A legal search of Florida case law was conducted to identify any recent challenges to existing laws or procedures relating to land development and its involvement in contributing to public bus transit to identify any existing controversies or issues. The search was intended to find any clarifications that the courts provide in the application of the law. The literature search included a review of Florida Development of Regional Impact (DRI) regulations and processes and the site impact analysis process used by the Florida Department of Transportation.

The study also included initiation of contact by email with 290 contacts nationwide, with follow-up by telephone to messages containing useful information. Contacts included staff from public bus transit agencies and land development planning staff from municipalities and counties served by transit. The initial roster of contacts was developed, in part, by identifying bus transit systems nationwide that are peers of transit systems in Florida, based primarily on size. The roster also included transit agencies that were identified through the literature review as being among the best-run transit systems in the nation. The initial roster of contacts also was developed, in part, by identifying those urbanizing counties in the United States that are served by transit and that are experiencing the highest population growth rates, according to U.S. Census 2000 data. These areas would tend to have the greatest amount of new development and redevelopment occurring, thereby potentially providing examples of how transit is accommodated as part of land development. In Florida, 12 counties are ranked in the top 100 fastest growing counties in the nation. These include Broward, Miami-Dade, Palm Beach, Hillsborough, Brevard, Orange, Duval, Lee, Lake, Collier, Volusia, and Polk counties.

All public transit agencies that provide fixed route bus service in Florida were contacted. In addition, a request for information was broadcast on three email listservs, including those sponsored by the Institute of Transportation Engineers, Transportation Planning Council; the American Planning Association; and the transportation demand management email listserv sponsored by the Center for Urban Transportation Research. 


\section{Legal Foundation for Land Developer Contributions}

This section of the report details the legal foundation in Florida for private sector involvement in contributing toward public bus transit services. The discussion addresses the question of what is possible and allowable in the way of engaging private sector contributions.

Florida's Constitution confers strong home rule powers upon local governments, providing them the authority to regulate through the enactment of ordinances and to impose special assessments, impact fees and other means to raise revenue. While noncharter counties have powers of self-government only as explicitly provided by State law, charter counties can do practically anything their electorates allow as long as actions of self-governance are not inconsistent with State law.

In the arena of land development, the legal authority to engage private sector contributions for transit facilities rests squarely upon the local government comprehensive planning process and the exercise of police power to regulate land development activities. Police power is a power of state governments to impose restrictions upon private rights for the purpose of promoting public welfare. States can delegate this police power to local governments.

One aspect of the problem of transit systems attempting to provide service is that residential and employment sites continue to expand outward into a growing suburbia. For a number of reasons, municipalities may elect to adopt an urban services boundary to improve the efficiency of public services delivery, direct growth and preserve rural areas. It is to the advantage of a transit system to operate in a municipality that has an urban service boundary (USB), also called urban growth boundaries (UGB), preferred growth areas (PGA) and urban development boundaries (UDB).

The land development process, which conceptually could provide an increment of funding (or in-kind land, amenities, etc.) with each new land development, has not traditionally been a significant source of funding for public bus transit. Instead, due to the historical reliance on government funding, transit system planning processes have been aligned more with the long range transportation planning process that is required by all metropolitan planning organizations (MPO). Transit systems complete yearly updates to five-year transit development plans (TDP), the information of which is incorporated into the long range transportation plan and funded yearly through the annual Transportation Improvement Program (TIP).

The TDP process does not strongly address the relationship among transit, land use planning, and urban service boundaries. Toronto is an example of a place where, unlike Florida metropolitan areas, transit development has strong regional influence, 
and transit can actually shape development location, density, and attributes. In Florida, transit has little influence on the comprehensive planning process and vice versa. Most Florida transit properties do not provide levels of transit service that could be a major force in shaping the land use planning process.

In Florida, transit planning focuses service development where there is likely to be the greatest demand, which is not necessarily where new land development is occurring. As a result, strategic planning for the maintenance and expansion of bus systems may or may not be completely aligned with the pattern of new construction and redevelopment activities of an area, which are controlled by market forces. Transit agencies may be justifiably hesitant to spread limited resources across a larger service area by expanding route coverage to newly developing areas. In this way, there is a critical disconnect between a transit agency marshalling its resources to best serve its mission, and harnessing the land development process for transit system development. This is especially true if land development is occurring in locations where transit service cannot reasonably extend.

The Local Government Comprehensive Planning and Land Development Regulation Act, Chap. 163.3161, F.S., not only establishes the power of local governments to control future land development to ensure stable and orderly growth but also requires them to do so. Local governments across the state have achieved this through their planning processes with varying degrees of success. However, there is recurring interest in concepts of establishing urban growth boundaries, directing land development inward, downtown revitalization and sustainable communities. This interest reflects a continued awareness that it is possible to use the local government comprehensive planning (LGCP) process and its implementing land development code to successfully align the interests of transit system development with land development activities.

This law states that no public or private development shall be permitted except in conformity with the LGCP. At the same time, all ordinances and programs adopted under the authority of this act must be developed and applied with sensitivity for private property rights. The LGCP must "...facilitate the adequate and efficient provision of transportation...."

Municipalities having populations greater than 50,000 and counties having populations greater than 75,000, which are designated within the boundaries of a metropolitan planning organization, must prepare a transportation element. The intent of the transportation element is to combine the planning for traffic circulation and parking facilities with all other modes of travel, including bus transit, into one integrated plan. ${ }^{2}$ This law provides the potential power of the comprehensive planning process to guide transportation system development. In particular, the law has the power to guide bus transit system development through the land development process.

${ }^{1}$ Chapter 163.3161(3), F.S.

${ }^{2}$ Chapter 163.3177(6)(J), F.S. 
In addition to land use and transportation elements, LGCPs must be economically feasible as assured through a required five-year capital improvements element (CIE) that is reviewed annually. The CIE must include an outline of principles to expand or increase public facilities as well as principles to correct existing deficiencies in public facilities. It must also estimate public facility costs, and provide for "...standards to ensure the availability of public facilities and the adequacy of those facilities...." ${ }^{\prime 3}$

Those standards are defined by concurrency, as provided in Chapter 163.3180 F.S., which states that public facilities, including transportation facilities, must be available to provide adequate service concurrently with the impacts from new development. This state law is implemented by local government concurrency management plans as guided by Florida Administrative Code $9 \mathrm{~J}-5$. Concurrency management planning directly affects local capital improvements programming and the land development process. In other states with growth management legislation, these are known as adequate public facilities ordinances (APFO).

While transportation concurrency has almost exclusively applied to roadway level of service ${ }^{4}$ some local governments in highly urbanized areas of Florida have used the requirements of concurrency as a tool for negotiations with land developers to contribute toward public bus transit improvements. Conversely, other local governments can negotiate with land developers to contribute toward public bus transit improvements in designated areas where state law grants an exception from roadway concurrency requirements. In these cases, the proposed development must otherwise be consistent with the adopted local government comprehensive plan. In addition, it must be a project that promotes public transportation or must be located within an area designated in the comprehensive plan for urban infill development, urban redevelopment, or downtown revitalization.

The 1999 Florida Legislature made changes and added new sections to Chap. 163.3180, F.S. regarding transportation concurrency, which was intended to make the planning environment more favorable to alternative modes of travel, including bus transit. ${ }^{5}$ The amendments included modifications for greater multi-modal inclusiveness, such as a multi-modal transportation district option. This type of district means that private motor vehicle mobility is secondary and priority is given to development design for the pedestrian with "convenient interconnection to transit."

\footnotetext{
${ }^{3}$ Chapter 163.3177(3)(a)1-4, F.S.

4 The 2002 edition of the Quality/Level of Service Handbook, issued by the Florida Department of Transportation, clarifies that a more accurate term for the commonly used phrase "roadway level of service," is "automobile/truck level of service".

${ }^{5}$ The complete language of the legislation can be found on Florida Sunshine Online at http://www.leg.state.fl.us/Welcome/index.cfm.
} 
The amendments provide for the use of multi-modal level of service standards when justified by professionally accepted level of service measurement techniques. The analysis should demonstrate that the existing and planned community design will provide an adequate level of mobility within the district. With the emphasis of such developments on internal capture of trips, and given that the legislation is concerned with "...an adequate level of mobility within the district...[emphasis added]," the opportunity exists for transit agencies to consider the development of bus circulator services within these districts.

The local government comprehensive plan sets the policy framework guiding new development. Land development regulations adopted by a local government implement the comprehensive plan by specifying minimum standards for development. The Florida Statutes (Chap. 163.3202, F.S.) provide specific standards regarding what land development regulations must contain, including provisions that public facilities and services, such as transportation meet or exceed the standards established in the local government capital improvements element. These improvements must be available when needed for the development. Development orders and permits are conditioned on the availability of these public facilities and services necessary to serve the proposed development.

The Florida Statutes require each local government to unify its set of land development regulations into one Land Development Code. State law explicitly encourages local governments to use such land development regulations as incentive zoning, plannedunit development, and impact fees, discussed later in this report. It is within the land development code that local governments can specify criteria for the type, amount, and placement of transit facilities and amenities. These requirements are based upon the size and character of the proposed land development. The specifications in the land development code are non-negotiable.

Unless a land development code specifies development size thresholds for the application of requirements to provide public facilities, there is no rule of thumb that expresses the relationship between the size of a development and the degree to which developers can be expected to contribute toward public transit. If requirements are not specified in the land development code, then the outcome is based on negotiations. For the largest developments, particularly those that are judged to have an impact on more than one county, a Development of Regional Impact (DRI) process of development review engages input from local, state and federal agencies. Typically, they are only the developments of regional impact for which public transit agencies are involved in the review process. However, it is the host local government that is ultimately responsible. Local governments have the power to decide upon the conditions set in a development order, after consideration of recommendations from other agencies.

A well-crafted land development code is at the heart of ensuring that transit facilities 
are provided. Such a code would reduce reliance upon negotiations. However, requirements in land development codes tend to run the risk of treating developments as "one-size-fits-all." This approach raises the possibility that requirements might not suit a particular development, or that minimum specifications actually become treated as the maximum expected of a developer without considering what is most desirable.

Public transit agencies rarely have the staff resources to stay on top of the myriad development proposals under review at any one time. It is up to the local host government to advocate on behalf of the transit agency. The best that a transit agency can expect is what a local host government is willing to negotiate.

Even in the case of developments of regional impact, in which transit agencies are usually involved, the local government needs to act as a strong and vigilant ally of public transit. It is often the case that the review process occurs over an extended period of time. The development concept may change repeatedly in response to market conditions. Changing conditions may necessitate follow-up reviews for which transit agencies may not have the staff resources.

The next section of this report, "Current Approaches for Engaging Private Sector Involvement," presents examples of both incentives-based approaches and regulatory approaches that have been successfully used to secure transit facilities or funds for operations. 


\section{Current Approaches for Engaging Private Sector Involvement}

This section addresses options that have been recently used in Florida for engaging private sector participation in contributing toward public bus capital facilities or operations. The options have been divided into two categories: non-regulatory (voluntary) or incentives-based approaches, and regulatory approaches.

A national search of case examples of non-regulatory approaches found that private sector land developer participation has been more active in contributing toward roadway improvements, light rail service, streetcar service (also fixed guideway) or private shuttles rather than fixed route public bus service. When there has been private sector participation, the participation has been from private commercial or retail businesses, independent and dependent special districts, employers, or property owners who are not in the land development business. With two exceptions, this study included only those examples in which a property owner also had land development interests.

Many mechanisms that potentially support public bus transit work better with the above groups rather than private sector land developers. Such mechanisms include:

- cost sharing agreements with private businesses to pay for nearby bus shelters

- advertising within public rights-of-way

- transit contributions in return for recognition

- employer-subsidized transit passes

- commuter choice tax benefits

In other cases involving public bus transit service development where land development interests are represented, such as in the case of a downtown development organization, it often turns out that private funds are not used but public mechanisms for raising revenue for public transit are used instead, such as special financing districts.

In another case, it appeared that transportation management organizations (TMO) might hold some potential for harnessing the support of private sector land developer participation, but the best examples of TMOs were effective because the organization's work was backed up by the existence of community financing districts, or local trip reduction ordinances in response to federal clean air requirements.

As a result, a multitude of initially considered case study examples of non-regulatory approaches ultimately fell away from inclusion in this report because they did not address the focusing features of this report, which were: 
- involvement by land developers

- cases of new land development or redevelopment

- providing funding or in-kind contributions to public bus capital facilities or operations

- under circumstances applicable to Florida localities

As a result, the examples of non-regulatory approaches are noticeably few. Developers often do not find incentives or reasons to believe that a mutual gain is available as a result of contributing to public bus transit service. However, there are a few cases below that provide some insight as to what circumstances allow for non-regulatory approaches to be successful.

\section{Non-Regulatory Approaches}

Non-regulatory approaches for engaging private sector land developer participation in contributing toward public bus transit facilities and operations hinge on effective negotiations in order to be successful. Negotiation is a means to achieve positive results for both parties regarding a specific project, within the context of the local regulations. Negotiation is often necessary when the cooperation of several parties is needed and it can be used to tailor a development result. Those negotiating for the municipality must be well versed in development financing in order to recognize what requests are too costly for the developer to accomplish. Negotiation is often laborintensive and expensive. It should not be used for every decision, but for complex situations involving many parties and there should be a defined process for negotiations. Local development opportunities should be such that developers will want to strike a deal and not go somewhere else to pursue business opportunities. The result of negotiations is a development agreement, the requirements of which are defined by the Florida Statutes. ${ }^{6}$ A development agreement is a legally binding contract between the developer and a municipality.

Negotiation can be a way to allow the developer to vest his rights against future changes in the municipality's regulations affecting his land in return for private contributions of public services to the municipality.

Incentive programs offered by local governments may be most effective when reinforced by local regulations, in order to form partnerships between local governments and the development community. Incentive programs may provide a reason for a developer to want to negotiate. Examples of incentives commonly offered by local governments include:

\footnotetext{
${ }^{6}$ Chap. 163.3227 , F.S.
} 
- density bonuses

- lower parking requirements

- expedited permitting

\section{Joint Development}

Joint development, from a transportation standpoint, involves coordinated ventures undertaken by the public and private sectors for the development of land above, below, or along transportation facilities. ${ }^{7}$

Joint development can have a variety of advantages to transit, including attracting new riders to the transit system by fostering commercial and residential projects on and adjacent to transit stations. In some cases, the negotiation process for development agreements can be expedited due to the mutual gains sought by both private and public development entities. Sometimes development agreements provide for sources of revenue for transit system operation and maintenance. Joint development can also assist local jurisdictions to recapture a portion of their past financial contributions. Furthermore, joint development can continue providing operating support by expanding the local property tax base and adding value to available local revenue sources. These opportunities can result in promoting transit-oriented development, reducing the cost of system expansion, and further involving private stakeholders.

Development projects listed as case studies under this category do not include those that came about as a fulfillment of responsibilities pursuant to a local government land development code or as a stipulation in an agreement under the DRI process, but rather as a voluntary and opportunistic arrangement in which both public and private parties had something to gain by combining resources.

\section{Daytona Beach, Florida}

VOTRAN is the public transit system in Volusia County. VOTRAN's involvement in new development along Daytona Beach was the catalyst for economic redevelopment. To secure the commitment of a developer for the expansion of a civic center and an existing hotel and the construction of a new hotel with restaurants, shops and a movie theater, the County had to remove some existing parking and prohibit driving along a one-mile stretch of beach. To restore required access to the public beach, the County needed to build a parking garage and enhance public transportation to the beach. In the meantime, VOTRAN received Section 5309 public transportation funds for capital expenditures from the Federal Transit Administration for the purpose of building a transit hub. The City and County needed the partnership with VOTRAN to marshal the

\footnotetext{
7 Urban Public Transportation Glossary, Benita H. Gray, ed., Transportation Research Board/National Research Council, Washington, DC, 1989.
} 
funds necessary for the parking structure and to establish the Beach Tram Service to ensure public beach access. In return, VOTRAN secured the placement of the Daytona Beach Intermodal Facility within the parking structure, using the federal funds. This established a major transit hub on the beachside and in the middle of a major redevelopment. ${ }^{8}$ In this case, the transit agency gained locational advantages for a new transit hub in return for providing public beach access and leveraging federal funds for parking garage construction.

\section{Portland, Oregon}

Bus transit centers, park and ride lots and bus bays resulted from a public/private partnership to build the airport MAX, a light rail to the airport in Portland. The partnership included Tri-Met, the Port of Portland, the City of Portland, and Bactel, a private developer, to fund the airport MAX in its entirety. No federal funds were used for this project. The agreement called for each party to contribute one quarter of the project cost. In return for its contribution, Bactel received the rights to become the main project contractor and the right to lease a prime parcel of land near the airport to develop a business district. In the case of Portland, developers are willing to contribute to light rail service, and less so for public bus service, because there is the strong perception that access to light rail service will make a property more desirable. ${ }^{9}$

\section{Bridgeport, Connecticut}

A joint development project involving three areas in Bridgeport incorporated an activist community and an economic role for the transit agency in the revitalization of areas surrounding transit service corridors. The transit agency worked closely with community and business leaders to foster revitalization of these areas. The transit agency received public and private monies to make pedestrian/transit street improvements, façade improvements, and bus stop improvements. ${ }^{10}$

\section{Regulatory Approaches}

From the viewpoint of economic development interests in a municipality or region, there is the desire by local governments to attract large employers that will create many high paying jobs. When employers scope out potential areas for relocating, they want three things: a predictable process for moving in, building, and developing their facility; a

\footnotetext{
${ }^{8}$ Ken Fischer, VOTRAN, phone conversation, 2/01/02.

${ }^{9}$ Francis Wambalaba, Senior Research Associate, CUTR, formerly with Portland, Tri-Met.

${ }^{10}$ From Joint Development and Fixed Route Bus Systems: Experience in Bridgeport, Connecticut, Greater Bridgeport Transit District, January 1985.
} 
receptive ear on the part of the local government; and information about a locality that is quantifiable. ${ }^{11}$

Beyond state and local law is the arena of land development negotiations, for which there are no rules. Except in the largest urban areas in Florida, such as Miami-Dade and Broward Counties, transportation concurrency is usually not the driving issue behind negotiating transit or even roadway improvements with land developers. Rather, they are issues relating to traffic flow, access and safety. The bottom line is that a local government can impose any requirements it wants upon a land development proposal, including stricter requirements than that specified in the land development code. Ultimately, if the local government's conditions are unacceptable, then the developer can either create a new site plan concept, decide not to develop the property, or locate the development elsewhere; however, the local government usually wants the development to proceed in order to increase the local tax base. The local government must balance this desire with ensuring that any minimum requirements of the land development code are met. The developer wants to maximize profits from the development. Usually, roadway improvements are costly and the developer will be willing to contribute transit improvements if it is a way to reduce local government requests for roadway improvements.

Due to the negotiation process, outcomes can vary greatly, even within the same jurisdiction. For example, in the City of Tampa, the development order for the International Plaza shopping mall, which opened in September 2001, required only that the developer build two bus shelters and pullout bays along two highways located onehalf mile from mall property. ${ }^{12}$ By contrast, when plans were under way to renovate and expand the Westshore Mall in 1999/2000, also located in Tampa, Hillsborough Area Regional Transit (HART) feared that they would lose a bus transfer location on mall property. However, the developer rebuilt a higher quality transfer center with access through the parking garage (a totally covered walk for bus riders), which provided the same level of access to the mall as exists for people parking their cars. This included a three-bus bay transit center with loading area, landscaping, and a bus stop. The developer also funded one third of the cost of bus shelters, totaling $\$ 21,000 .^{13}$

The Florida Department of Transportation exercises much stricter control regarding specifications for roadway improvements on state roads, but has no control regarding on-site issues. Local governments can negotiate with land developers regarding on-site

\footnotetext{
${ }^{11}$ Notes from speech by John Dawsman, former Economic Development Director for Hillsborough County, given at the $6^{\text {th }}$ Annual Impact Fee Roundtable 2000, November 15-17, Tampa, Florida.

${ }^{12}$ Ed Crawford, Hillsborough Area Regional Transit, phone conversation, 10/9/02. This development received an extraordinary amount of public criticism over the lack of bus service, which opened the door to renewed negotiations. The issue was covered by an August 30, 2001 article in the Tampa Tribune and two articles in the St. Petersburg Times, dated September 3 and September 6, 2001.

${ }^{13}$ Sharon Dent, Executive Director, Hillsborough Area Regional Transit, email communication, 2/20/02. For further information on the subject of ensuring public transit access to private property, see Public Transit Access to Private Property, National Center for Transit Research, sponsored by the Florida Department of Transportation. Prepared by the Center for Urban Transportation Research, Tampa, Florida. August 2000.
} 
issues. For example, if the land development code specifies maximum floor area ratios (FAR) for a development in a particular zoning classification, it is the local government's prerogative to offer the developer an increase in FAR (which could make the development more profitable) in return for other design features, amenities, or contributions. Ultimately, the end result varies widely from one locality to another, depending upon what the local government wants.

\section{Local Land Development Regulations}

Nationally, land development regulations (LDR) for a municipality usually include, at a minimum, a zoning ordinance and a subdivision ordinance and specify what a developer must do in order to receive a Certificate of Occupancy.

As outlined in the earlier section on the "Legal Foundations for Private Sector Contributions," the local government comprehensive planning process has the power to guide transit-friendly development patterns. It also has the power to support public transit, as demonstrated by the capital improvements element. Local ordinances that guide land development, also known as land development regulations or the land development code, also provide the foundation to engage private sector land developers to contribute to public bus transit capital facilities and operations costs.

All local ordinances must be consistent with the local government comprehensive plan (LGCP). These ordinances include zoning, subdivision, and impact fee ordinances and adequate transportation facility regulations that set level of service standards. They must serve as implementing tools of the LGCP. Therefore, it is important that the LGCP strongly and clearly provide the policy foundation for transit development as a part of the land development process, otherwise the implementing ordinances will lack effectiveness.

Identification of public transportation corridors is one way to establish the expectation, as provided by the LGCP, that contributions toward public bus transit facilities will be a condition of land development. The Transportation Element of the Comprehensive Plan for the City of Port Orange, Florida, provides an example of clear policies that support transit development. Excerpts from this document are included in Appendix A of this report. One of the most important features of the policies in the Port Orange Transportation Element is the identification of "public transportation corridors." These are areas along roadways that are served by existing and proposed bus routes. Along these corridors, the City ensures adequate roadway level of service, encourages site developments that support transit, requires on-site access for a bus stop and the incorporation of transit-friendly design, and commits the City to provide improvements to existing bus stops. 
The land development code implements and carries out the intent of the LGCP; however, not all land planning policies are or can be necessarily translated into effective land development regulations. At best, land development regulations are instruments that ensure a minimum result and that do not always capture the nuances of good land planning. They are difficult to craft in a way that promotes the best possible outcome for all parties. The best results are more likely to come about if all parties work together to achieve a result that represents what is best for the locality as a whole. This is difficult to achieve because the developer wants a maximum return on that particular property investment and the public sector wants to minimize adverse impacts. The collaborative effort also takes more time and planning staff expertise than a locality can often afford. Therefore, the minimum standards imposed by the LDC often reflect the final outcome. The advantage of providing specifications in the LDC is that they lend some degree of certainty about minimum expectations of the developer and a starting point for negotiations in jurisdictions that have conditional zoning.

LDRs can specify standards for transit accessibility, such as providing a location and construction of bus stops and the development of a sidewalk system that provides easy access from the development to transit stops. A transit amenities survey of Regional Transit System (RTS) bus riders in Gainesville was conducted, which found that the presence of a bus shelter and bench were considered to be the most important bus stop amenities. ${ }^{14}$ The Florida Statutes explicitly encourage local governments to use such LDRs as tax increment financing, incentive zoning, planned-unit development (conditional zoning), and impact fee ordinances.

\section{Tax Increment Financing (TIF)}

Tax increment financing (TIF) harnesses public money, but this mechanism is included in this report because TIF districts are rarely established without the commitment of a land developer. Tax increment financing is a method of funding public improvements in an area slated for redevelopment. This is done by capturing, for some period of time, all or a portion of the increased tax revenue that may result if the redevelopment stimulates private investment.

TIF bonds are a financing option that does not count against a municipality's bonded indebtedness. The TIF is financed by subsidizing one city's developments with taxes from another municipal taxing authority. For example, sources of money for contributing to the TIF fund include city property taxes, county property taxes, school district taxes and sales taxes. No state or federal funds go to TIFs. Typically, a redevelopment agency is established to oversee the TIF district. The redevelopment agency solicits developers to perform the public improvements. Developers generally

\footnotetext{
${ }^{14}$ Dr. Linda B. Crider. "Multi-Modal LOS 'Point' Level of Service Project, Final Report," Department of Urban and Regional Planning, University of Florida, Gainesville, August, 2001, p.55.
} 
do not reap the benefits unless they own enough surrounding land to capture the positive externalities from the public improvements.

The tax increment is diverted to an established redevelopment agency or a fund earmarked for retiring the debt on the project. The State must have enabling legislation and sometimes a constitutional amendment allowing TIFs. At least 33 states, including Florida, allow TIFs of some kind. Permitted activities for TIF projects can include providing infrastructure. Proceeds are only to be used in the TIF area. Other bonds that can be used are general obligation bonds, lease-revenue bonds, industrial revenue bonds, and special assessment or other municipal improvement bonds. The feasibility of TIFs is difficult to determine because it is based upon economic projections, market analysis, and appraisals.

\section{Orlando, Florida}

The Downtown Orlando Lymmo is financed by a Tax Increment Trust Fund of the Orlando Community Redevelopment Agency. The Lymmo, established in 1997, is a free downtown bus service that can deliver passengers within a block of any downtown location in 10 minutes or less. Lymmo is a service provided by the Central Florida Regional Transportation Authority (LYNX). The Community Redevelopment Agency (CRA) was set up to pursue revitalization activities within a designated Redevelopment Area, with one emphasis to address long-term transportation needs. The CRA is a part of the City Downtown Development Board, which was created by a special act of the Legislature in 1971 and is guided by an advisory board.

\section{Zoning}

Zoning is a police power that a City or County uses to divide land into areas or districts (zones) for which particular land development regulations apply. Each zone may specify allowable uses for property and regulates land use features such as lot size, building density, building placement and setbacks, and other standards. There are two different types of zoning described here.

\section{Incentive Zoning}

Incentive zoning provides the opportunity for private developers to voluntarily donate funds for public amenities in exchange for development advantages, such as opportunities to save or make money. Incentive zoning provides flexibility in planning for a land development by granting the developer additional development capacity in exchange for providing specified public facilities, benefits or amenities that the local government seeks. Traditionally, these facilities have included public plazas, open 
space, or affordable housing, but the local government can also use this tool for transit facilities.

The use of incentive zoning for transit has more often been applied to light rail. For example, the Minneapolis zoning code contains provisions for granting floor area ratio (FAR) bonuses in exchange for the construction of transit stations at light rail stops according to standards as specified in the zoning code. However, similar incentives might work when applied to developments near premium bus service corridors.

\section{Orlando, Florida}

Orlando's Land Development Code provides for bonuses to developers who set aside at least one percent of the total construction costs for the development and contribute this to the city. The City will use these funds in accordance with an adopted comprehensive mass transit facilities program, to provide access to mass transit services appropriate to the type of activity center in which the development is located. Bonus parking spaces also are available for a contribution to the mass transit fund.

\section{Rosslyn, Virginia}

The Rosslyn bonus program provides that additional floor area can be granted in exchange for not only urban design benefits but also for off-site amenities and economic development benefits. ${ }^{15}$ Rosslyn is located in Arlington County, in proximity to downtown Washington, D.C., Georgetown, and federal employment centers. New zoning regulations for Rosslyn were adopted in 1996, which established the base density in the downtown at a 3.8 floor area ratio (FAR), which made most development subject to the site plan review process. Through this process, additional density (referred to as bonuses or premiums) is granted to the developer in exchange for providing public amenities. These have included connections of high-density development to transit stations of the Washington Metro Area Transit Authority. Density bonuses can also be granted to developers in exchange for cash contributions to the Rosslyn Fund.

The Rosslyn Fund provides community benefit improvements in Rosslyn from payments made by developers. The fund could be used for transit though it has not been to date. Transit in Rosslyn is primarily the Metro subway system, which was developed before the Rosslyn Fund was created. The Fund has been used for improvements to a performance theater and for design services. A small sum $(\$ 25,000)$ was contributed to

\footnotetext{
${ }^{15}$ Marya Morris, Incentive Zoning: Meeting Urban Design and Affordable Housing Objectives, Planning Advisory Service Report Number 494, American Planning Association, Chicago, September 2000.
} 
a shuttle service between Rosslyn and Georgetown in Washington, DC, which began in September, 2001. ${ }^{16}$

\section{Conditional Zoning}

A conditional use district is one in which a permit to develop is issued only when certain conditions are met, in exchange for allowing a use of the property not otherwise applicable to land similarly zoned. The attachment of special conditions upon a development by a local government allows for a rezoning of the property that makes the property more profitable.

Conditional zoning is often used in dense central cities and in growing suburban areas. Examples of uses that may be subject to conditions are those that attract a lot of people, or may create traffic congestion or noise, place burden on infrastructure or cause some adverse effect to public welfare or safety. These include schools, churches, hospitals, assisted living facilities, clubs, open-air recreation facilities and shopping centers. Specific conditions might include access requirements or the placement of transit-oriented design requirements.

Conditional zoning is also applied in the form of planned unit developments (PUD). PUDs exist where there are PUD ordinances or enabling provisions in subdivision ordinances. PUDs are a method of residential development in which an area within a specified minimum contiguous acreage is developed as a single entity. The plan for the PUD contains one or more residential clusters in which lot area, setback and height restrictions may be waived and which may include commercial, public or quasi-public uses for the primary benefit of the residential development. ${ }^{17}$

\section{Orlando, Florida}

The City of Orlando encourages transit-oriented design by placing conditions on development when possible. Equally important, Orlando's Land Development Code includes standards similar to LYNX's Mobility Design Guidelines for developing in a transit-friendly manner. The Mobility Design Guidelines are helpful to the city staff who review new developments and who can place conditions on development. The Central Florida Mobility Design Manual ${ }^{8}$ includes a mobility design checklist for use by architects, planners, and engineers when creating a site plan. The checklist covers, among other things, transit circulation, transit stop and terminal design, building

\footnotetext{
${ }^{16}$ Betts Abel, Arlington County Public Affairs Department.

${ }^{17}$ Tomioka, Ellen Miller and Seishiro, Planned Unit Development: Design and Regional Impact. New York: John Wiley \& Sons, 1984.

${ }^{18}$ Central Florida Mobility Design Manual, Central Florida Regional Transportation Authority (LYNX), prepared by Glatting Jackson Kercher Anglin Lopez Rinehart, Inc. in association with Herbert Halback and Associates, Inc. Revised edition, 2000.
} 
location, and building design. The Guidelines are applicable during the stages of land development that involve the subdivision of large parcels, the site planning stage, and the final stages prior to issuance of a building permit and certificate of occupancy.

LYNX also provides the Customer Amenities Manual ${ }^{19}$ that provides detailed guidance for the design of bus passenger amenities. In some cases, private developers are required to provide property easements to accommodate the most appropriate and beneficial transit stop and install improvements within the road right-of-way as a condition of approval of their development. For example, the developer for the Colonial Town Center in Orlando provided land for a "Super Stop" bus shelter close to major stores.

There are five types of bus stops based on the number of daily passengers and the number of routes served. Each of the five is located within a certain land use classification. The Super Stop serves neighborhood focal points and community centers and is located near parks, activity centers, schools, government centers, and shopping centers. The Super Stop consists of multiple covered shelters with seating, bus staging lanes or bus bays, bike storage, landscaping, information kiosk, trash receptacles, telephones, and a water fountain.

The land for the Colonial Town Center Super Stop was negotiated as a 20-year lease at no cost to LYNX and was required by the Orlando Planning Department before permitting began. The results of the negotiation process were advantageous to LYNX because of the location of Colonial Town Center, which is important as a transfer location for routes.

\section{Counties in Virginia}

Several examples are provided here regarding the use of conditional zoning in Virginia. These include examples of highly urbanized areas where entire transportation management plans are required of the developer as a condition of development approval.

Fairfax County--Fairfax County refers to their conditional zoning as a "proffer system", a system in which developers agree to provide public facilities necessary to meet local standards in exchange for an advanced date of project approval. The Virginia state legislature granted Fairfax County and other counties broad conditional zoning power in the early 1970s. The proffer system coordinates transportation development decisions among private developers, planners with the state department of transportation, and local land use planners. Conditional zoning allows local government to make approval of rezoning contingent upon the receipt of proffers from the party seeking the rezoning.

${ }^{19}$ Customer Amenities Manual, Central Florida Regional Transportation Authority (LYNX), prepared by Herbert Halback and Associates, Inc., 2000. 
Although historically, proffers have been used largely for on-site improvements, they can also be used for off-site improvements, such as schools, sewers, roads, and transit improvements.

Proffers have the advantage of providing flexibility in resolving site-specific problems that may not be addressed easily under general formula approaches to developer contributions. The use of proffers often results in time savings in the case of direct land dedications or developer construction of facilities rather than public acquisition or construction. Proffers can only be sought for facilities that are required by the rezoning. ${ }^{20}$

Prince William County-Another example is Prince William County, located in the Washington, D.C. area. The County transportation department encourages private land developers to proffer conditions above and beyond those normally required. These conditions are intended to mitigate impacts resulting from the proposed use of the land. Proffer statements are reviewed as a part of the rezoning application, and are accepted by the Board of County Supervisors with its approval of a rezoning application. Proffers from private land developers have included those for transit improvements, such as the construction of bus shelters, the provision of commuter lots, and the provision of bus or shuttle service within large developments.

Arlington County - Commonwealth Atlantic Properties proposed a redevelopment plan for Potomac Yard in Arlington consisting of 2.9 million square feet of office and commercial space and 1.4 million square feet for residential and hotel use. The plan also includes new streets, parks, and other amenities that are intended to make the development an attractive, coherent whole. As a condition of development, the developer agreed to a transportation management plan that implements transportation demand management (TDM) and transportation systems management (TSM) strategies designed for the purpose of achieving a transit/bike/walk mode share of 40 percent.

Requirements of the plan included access to the CommuterPage.com web site. The web site is a service of the Arlington County Commuter Assistance Program. The web site contains commuter service information, including complete transit system information for the more than seven public transit systems serving the area, as well as private transit systems.

Requirements of the plan also included provision of space and build-out of a small transit store, installation of $\$ 30,000$ worth of electronic kiosks providing access to transit information and a contribution of $\$ 75,000$ each for the purchase of two new Arlington Transit buses to enable extension and enhancement of the development's transit services.

\footnotetext{
${ }^{20}$ Robert D. Vander Lugt and Salil Virkar, Coordination of Transportation Planning and Land Use Control: A Challenge for Virginia in the $21^{\text {st }}$ Century, Virginia Transportation Research Council, Charlottesville, June 1991.
} 
The transportation management plan also called for coordinated parking management, which included the provision of reserved, conveniently located and free vanpool parking spaces, and daytime parking for commuter buses serving the office uses in the development. The parking plan also called for single occupant vehicle parking only at fair market rates.

The transportation management plan is required to be coordinated with the Arlington County Commuter Assistance Program, to which the developer was required to provide a contribution. The developer was also required to contribute to the Metrochek Match Employer Incentive Program, which provides a cash incentive for employers to subsidize transit passes for employees. The transportation management plan also required the developer to devise and implement, in coordination with the County, a local transit service plan to provide high quality transit service to the site prior to the completion of a planned transitway.

As a part of site plan conditions, there also was the requirement for the contribution of right-of-way for a transitway. The transitway is a corridor shared by transit systems and which excludes other vehicular traffic. All land adjacent to the transitway was required by the site plan conditions to be developed according to adopted Urban Design Guidelines and consistent with the Transit Corridor Plan.

The site plan conditions also required the developer to pay the cost of interim and permanent improvements in the median strip between the transit corridor and the street. In addition, the developer was required to pay a transit station contribution, equaling $\$ 0.10$ per square foot of gross floor area represented in the final site plan, for transit stations and related improvements consistent with the Transit Corridor Plan. This contribution would go toward the installation of transit stations and shelters outside of the transit corridor to serve the buildings within the Potomac Yard development. The developer was also required to install initial transit stations and shelters serving the existing transit system before the transit way was completed. ${ }^{21}$

Arlington County - In another location in Arlington County, plans for the Crystal Mall and Plaza, providing retail and office space, also required the developer to devise a transportation management plan (TMP) as a condition of development. The TMP required the developer to provide for the relocation of a bus stop and staging areas to a Metrorail Station, including a minimum of four full-size active bus stops, including seats, signage, upgraded lighting, wider sidewalks, saw-tooth stop configuration, paint and striping, special pavement treatments for pedestrian crosswalks, and landscaping enhancements, all with a total cost not to exceed $\$ 300,000$. The developer also was required to provide the following:

\footnotetext{
${ }^{21}$ Potomac Yard Transportation Management Plan, as provided by James Hamre, Arlington County, VA.
} 
- public restrooms for use by bus drivers within 600 feet of the relocated bus stop

- one bus/van carpool shelter installed within Crystal City to replace an existing bus layover area

- two electronic transportation information displays providing public access to transit information and to the CommuterPage.com web site or payment of an inlieu fee of $\$ 10,000$

- assurance that building facades will not interfere with or preclude the option for a planned transitway along the adjacent access drive

- cooperation with future efforts to establish a special transportation district in Crystal City

- establishment of monthly parking rates for single occupant vehicles that are consistent with comparable office buildings located in the Arlington County development corridors

- conveniently located parking spaces for ridesharing vehicles

- payment of $\$ 24,000$ or provision of free office space for the Crystal City Commuter Store for two years

- maintenance of an active membership with Arlington Transportation Partners (ATP), a local transportation management association, on behalf of the property management team

- provision of transit promotional services such as a new-tenant package to include site-specific transit-related information, transit information as part of recruiting and employment materials, and a transit advertising program for distributing transit information to tenants and employees four times per year

\section{Level of Service Mechanisms}

The discussion below summarizes the existing use of level of service measures and standards for enlisting land developer participation in contributing toward bus facilities and operations.

\section{Concurrency and its Application}

The keystone of growth management in the State of Florida is the concept of concurrency, as provided in Chapter 163.3180 F.S., which states that public facilities, including transportation facilities, must be available to provide adequate service concurrently with the impacts from new development. In other states with growth management legislation, these are known as adequate public facilities ordinances (APFO).

This state law is implemented by local government concurrency management plans as guided by Florida Administrative Code $9 \mathrm{~J}-5$. Concurrency management planning directly 
affects local capital improvements programming and the land development process. It is typically in the most urbanized counties, such as Miami-Dade and Broward Counties, that concurrency is the driving issue behind negotiating roadway or transit improvements. Then local governments can negotiate aggressively for such things as operating subsidies to extend bus routes.

Florida's concurrency law, as originally written for transportation, has been almost exclusively applied to mean roadway concurrency. Over the years, roadway concurrency has changed gradually to provide local governments with more flexible options, such as:

- Transportation concurrency exception areas (TCEA) for "projects that promote public transportation";

- Transportation concurrency management areas (TCMA) that can incorporate viable alternative travel modes; and

- Exclusions for public transportation facilities from having to meet roadway concurrency requirements.

There are now established methods for measuring level of service for bus transit, bicycle and pedestrian modes of travel. Nonetheless, for the purposes of meeting transportation concurrency, the available methodologies currently in use for measuring level of service (LOS), as well as Florida's statewide minimum LOS standards and the LOS standards adopted by local governments have been almost exclusively roadway LOS standards. Maintaining these roadway LOS standards has been the basis upon which local governments make arrangements with private sector land developers to pay the costs of transportation improvements.

\section{Lee County, Florida}

More commonly, Florida municipalities provide standards in their land development codes for the provision of access to public transit rather than service standards. The Lee County Land Development Code provides an example of this, in which public transit facilities include paved walkways, signage, and shelters. ${ }^{22}$ These are all physically fixed capital facilities, comparable to roadway through lanes, turn lanes and traffic signals. Typically, if land developers do provide public transit facilities, based on conditions in the development order, they will be fixed capital facilities, such as sidewalks and shelters, which provide physical access from the new development to public transit service. After the development is complete, the land developer often leaves. As a result, the provision of capital facilities is attractive to the municipality because it has lasting value. The provision of capital facilities is attractive to the developer because it requires no ongoing commitment.

\footnotetext{
${ }^{22}$ Lee County Land Development Code. Sections 10-441 through 10-443. See also the Hillsborough County Land Development Code. Site Development Design Standards. Sections 6.03.00-01.
} 


\section{Orlando, Florida}

The City of Orlando Growth Management Plan (the comprehensive plan) provides an example of public transit policies that incorporate transit level of service standards that are based upon quality of service from the passenger perspective. Objective 1.13 states that the City will prioritize transit headway improvements along designated transit corridors throughout the planning period, with 59 percent of the designated transit service corridors within the Transportation Concurrency Exception Area (TCEA) maintaining or improving a 30 -minute weighted average headway by $2005 .^{23}$ Policy 3.3.5 states that the first priority for funding transit improvements shall be based upon improving headways on existing routes. ${ }^{24}$

\section{Hillsborough County, Florida}

In 1999, Hillsborough County determined that roadway concurrency would not be met with road improvements made to mitigate traffic from The Preserve, a large residential development in the Hidden River area. To meet concurrency requirements, the developer entered into an escrow agreement with Hillsborough County Regional Transit (HART), in which $\$ 10,000$ was paid into an account utilized to pay for bus service extension to the area. HART has ten other similar agreements for paying for bus service. $^{25}$ This arrangement can be very useful to initiate bus service to see if the ridership exists to continue the service but it does not provide a means to maintain the service. As in the case of the Hidden River area, businesses along Hidden River Parkway offered no support to provide funds to maintain the service. Ridership was low and as a result, bus service was discontinued in December 2001.

\section{Broward County, Florida}

Broward County Transit (BCT) has several contracts with cities for providing community shuttles through developer funding. Two such developments that provided for shuttle services are described below, as part of development agreements. These agreements, entered into with the Cities of North Lauderdale and Pembroke Pines, represented cases in which the shuttle service was successful for the purpose of meeting concurrency requirements only because there were a small amount of trips to mitigate.

A third development is a development of regional impact that is not yet finalized and is, as of this writing, in the stage between the assessment by the regional planning council

\footnotetext{
${ }^{23}$ City of Orlando. Transportation Element, p. 14.

${ }^{24}$ City of Orlando. Transportation Element, p. 26.

${ }^{25}$ Les Weakland, Senior Planner, Hillsborough Area Regional Transit. Phone conversation, 2/20/02.
} 
and the Development Order stage. The Lightspeed DRI is located at the Cypress Creek Tri-Rail Station, and involves the Cities of Ft. Lauderdale and Oakland Park. The DRI includes the location of a mixed-use development at a park and ride lot owned by the Florida Department of Transportation.

The developer originally claimed a mode split rate that indicated high transit usage. The County did not see that such a high rate was justified. The County worked out an arrangement with the developer to commit to funding a shuttle to justify the rate. Currently, there are shuttles running during the morning and evening peak hours when Tri-Rail is in service. The developer will fund a shuttle to continue to run between the morning and evening peak times, so that the shuttle is running throughout the day.

North Lauderdale-The Broward County Development Management Division issued to two developers, Notifications of Failure to Satisfy Broward County Concurrency Standards for the regional transportation network. The proposed developments involved the establishment of a cemetery and an industrial facility. The notices indicated that the applications for approval of the plats did not satisfy the concurrency standards for the regional road network, as defined in the Broward County Land Development Code. As a result, Broward County entered into an agreement in which the two developers will provide a three-year contribution toward the maintenance, operation, and equipping of a community bus service. The County agreed to lease a vehicle to the City of North Lauderdale to operate the service. This agreement will mitigate the traffic impacts to the two plats so that the plats will satisfy Broward County concurrency standards. The two developers agreed to pay a share of the cost proportionate to each plat's traffic impact, totaling $\$ 159,600$.

The shuttle will provide free fixed-route service to connect with regular County bus routes. The service will be offered five days per week for a minimum of 40 hours per week. The City agreed to operate the service, while the County agreed to provide drivers, transit planning assistance, printed bus route timetables, and signposts.

Pembroke Pines-Similarly to the North Lauderdale situation above, the Broward County Development Management Division issued Notifications of Failure to Satisfy Broward County Concurrency Standards for the regional transportation network to the City of Pembroke Pines for a plat for a charter school and to the South Broward Hospital District for a hospital. The notices indicated that the applications for approval of the plats did not satisfy the concurrency standards for the regional road network, as defined in the Broward County Land Development Code. As a result, Broward County entered into an agreement with the South Broward Hospital District (SBHD) that the SBHD would provide a three-year contribution toward the maintenance, operation, and equipping of a community bus service. The County agreed to lease two vehicles to the City of Pembroke Pines to operate the service. This agreement will partially mitigate the traffic impacts of the hospital plat so that the plats will satisfy Broward County concurrency standards. The SBHD agreed to pay $\$ 90,000$ to the City of Pembroke 
Pines to operate the shuttle. Non-transit arrangements were made to satisfy the concurrency requirements of the school.

\section{Transportation Concurrency Management Areas}

Transit level of service (LOS) standards used for concurrency purposes have been used in very few places. The City of Miami has used a "transportation corridors" approach, in which overall LOS is measured by aggregating the service capacities of parallel highway and transit facilities in designated corridors. Instead of measuring service capacity by how many vehicles can be accommodated by the system, service capacity is measured by how many person-trips can be made within the designated peak period. For example, if a highway within one of the corridors is operating at capacity but few people are riding MetroRail, then the aggregated measure of the level of service will indicate that capacity is still available within that corridor. Using such an approach, this would suggest that a developer could contribute toward the cost of higher frequency bus service in a corridor in order to meet concurrency. This may also have applications with bus rapid transit.

\section{Transportation Concurrency Exception Areas}

Transportation concurrency exception areas have been implemented, with the result of providing public transit facilities. It is useful to review here how they work.

Chap. $163.3180(5)(a)$ and (b), F.S., state that:

A local government may grant an exception from the concurrency requirement for transportation facilities if the proposed development is otherwise consistent with the adopted local government comprehensive plan and is a project that promotes public transportation or is located within an area designated in the comprehensive plan for:

1. urban infill development

2. urban redevelopment

3. downtown revitalization, or

4. urban infill and redevelopment under s. 163.2517.

An urban redevelopment area is defined by statute as an economically distressed area, designated by a local government where public services, including transportation, are already available or are scheduled to be provided in an adopted 5-year schedule of capital improvements. More than 50 percent of the area is within $1 / 4$ mile of a transit stop or a sufficient number of such transit stops will be made available concurrent with the designation. 
The Florida Administrative Code (FAC), Rule 9J-5.0055(6) defines areas that can be established as concurrency exceptions. Implementation guidelines include the following:

- The transportation concurrency exception area must be compatible with and further the elements of the local comprehensive plan.

- The size and boundaries of the area must be supported by data and analysis that demonstrates consistency with the Rule's requirements. Local government must coordinate the establishment of an exception area with the Department of Transportation and the local metropolitan planning organization.

- Transportation concurrency exception areas may transcend jurisdictional boundaries when appropriate and must be designated in each applicable comprehensive plan consistent with this Rule.

- Local government should adopt guidelines as an amendment to its comprehensive plan that include strategies to address transportation needs of the exception area.

Referring to those areas designated by statute, the amount of land that may be included in the exception area must not be more than 10 percent developable land. Density for residential development and floor area ratio for non-residential development also are specified.

\section{Gainesville, Florida}

The City of Gainesville uses two Transportation Concurrency Exception Areas (TCEA), within which most of the improvements required by developers are transit related. The goals of the Gainesville TCEA include urban redevelopment, infill development, transportation choices, desirable urban design, residential and non-residential mixed use, and streetscaping/landscaping of roadways within the city. The Gainesville TCEA is an Urban Redevelopment Area and is subdivided into two zones, A and B.

Zone A consists of the city's inner core and includes the University of Florida campus. Zone $B$ is further west and north. Each zone is treated differently under the TCEA. Zone $A$ contains abandoned sites that have been difficult to redevelop because of transportation concurrency problems. The priority in Zone A is to provide incentives to developers. Multi-modal transportation modifications are funded by the City, the Community Redevelopment Agency, federal and state governments, and other grant funds. Modifications required by safety or operating conditions, which are unrelated to concurrency, are provided by the developer. 
Zone B does not require the subsidies that Zone A does. The City provides specified standards that developers must meet according to the size and impact of the project. Developers can choose from a list of requirements that include traffic signals, dedicated turn lanes, bus pass programs for residents or employees of the development, payments to the regional transit system which will add or increase the frequency of bus service, ride-sharing or van pooling, participation in a TDM program, or provision of shading over sidewalks. ${ }^{26}$

According to a Gainesville planner, the goal of the TCEA is to not do road widening. For example, Plaza Royale, which was a former Scotty's in a deteriorating area in Zone A, is now mixed-use development, with the residential component currently being built. The developer met TCEA standards, and also funded bus shelters, sidewalks, crosswalk improvements, all of which the city could not have afforded. ${ }^{27}$

\section{Miami-Dade County, Florida}

Miami-Dade County successfully negotiated on behalf of the transit agency in coordination with the land developer to implement a Metrobus Transit Terminal as part of the Kendall Town Center.

The Kendall Town Center is being developed as a new downtown for the County's fastest-growing suburban area. The development will include 400,000 square feet of office space, 1.35 million square feet of gross leasable retail space, a community medical center, elderly housing, a theatre, and a hotel.

While this is a Development of Regional Impact, the concurrency regulatory mechanisms in the comprehensive plan and the land development code were the determining factors for successful negotiations. These include Objective 8B of the Mass Transit Sub-Element of the Comprehensive Development Master Plan (CDMP), which states:

In the planning and design of rapid transit sites, stations and transit centers, high priority shall be given to providing a safe, attractive and comfortable environment for pedestrians and transit users; such amenities shall include weather protection, ample paved walkways, sidewalks, lighting, and landscaping and ancillary uses that provide conveniences to transit patrons such as café, news stands and sundries sales.

To implement this section of the comprehensive plan, Section $C$ of the Miami-Dade Compliance Amendments Ordinance No. 99-42, April 27, 1999 states that a proposed

\footnotetext{
26 "Using TCEAs to Increase Sustainability," Florida Sustainable Communities Sarasota Workshop, 25-28 July 1999. http://edesign.state.fl.us/fdi/fscc/news/wkshp/sara/oneila.htm

${ }^{27}$ Onelia Lazzari, City of Gainesville, phone conversation, 9/21/01.
} 
development will not be denied a concurrency approval for transportation facilities, provided that the development is otherwise consistent with the adopted CDMP and it meets the following criteria:

The proposed development is located inside the Urban Development Boundary (UDB), and directly and significantly promotes public transportation by incorporating within the development...a Metrobus terminal for multiple Metrobus routes... ${ }^{28}$

As a result, provisions are contained in the proposed plan for the developer to pay for and provide the following transit amenities:

- six saw-toothed bus bays

- a covered waiting area with sitting furniture

- a restroom facility for bus operators

- a kiosk/transit information center

- 40 park-and-ride spaces reserved for transit users

\section{The Latest Statutory Amendments to Concurrency}

The 1999 Florida Legislature made changes and added new sections to Chap. 163.3180, F.S. regarding transportation concurrency, which were intended to make the planning environment more favorable to alternative modes of travel, including bus transit. ${ }^{29}$ The amendments included modifications for greater multi-modal inclusiveness, such as a multi-modal transportation district option, in which private motor vehicle mobility is secondary. The amendments make an allowance for the use of multi-modal level of service standards when justified by professionally accepted level of service (LOS) measurement techniques.

Please refer to the last section of this report, "Future Considerations for Interactions with Developers," for a discussion of future potential applications of this new law.

\section{Impact Fees}

An exaction is the general term used to describe the arrangement in which the developer must provide or finance the provision of certain public facilities, in exchange for a project's approval. The exaction covers the costs of growth attributable to the project. Impact fees are a type of exaction.

\footnotetext{
${ }^{28}$ Correspondence from Danny Alvarez, Director, Miami-Dade Transit, to Ann Pope, Development Manager, RouseWest Dade, Inc., Miami, Florida. n.d.

${ }^{29}$ The complete language of the legislation can be found on Florida Sunshine Online at http://www.leg.state.fl.us/Welcome/index.cfm
} 
Impact fees nationwide originally evolved as a type of fee in lieu of land dedication for public facilities. The advent of the use of impact fees in Florida in the early 1970's actually began as an unsuccessful effort by local governments to lobby the state legislature to establish an excise tax upon building materials. While the Florida Constitution prohibits taxation not otherwise legislatively permitted, it does not prohibit fees. Because of the failure to establish a tax, governments turned to the use of fees.

A tax is not a regulation but a means to raise revenue and there are no geographic restrictions upon where revenues are collected or spent. Impact fees are a police power regulation, the primary purpose of which must not be to raise revenue. Impact fee ordinances that raise excessive amounts of revenue can be struck down, although they have the potential to be a good source of revenue if the rate of development is high. The revenues that are raised by the impact fee from a land development must be spent for the benefit of that development or within a designated impact fee zone or subdivision.

Since their introduction in the 1970s, impact fees have been challenged in Florida courts on the basis of the unconstitutional exercise of home rule power, the unconstitutional exercise of police power, establishment of an invalid tax, and denial of constitutionally guaranteed equal protection. For example, the Florida courts struck down early impact fee ordinances as unauthorized forms of taxation because the fees did not relate specifically to their ultimate use. In Broward County v. Janis Development Corp., the court found that the fee was a tax because it did not specify where and when the monies would be used, even though it did specify the purpose, road and bridge construction for a high-density development. ${ }^{30}$

Four other landmark Florida court cases have since defined the required elements of impact fee ordinances in order to withstand legal challenges. ${ }^{31}$ In the earliest case, Contractors \& Builders Association of Pinellas County v. City of Dunedin, the courts upheld the validity of impact fees, in principle, and set the ground rules for the use of impact fees in Florida municipalities:

\footnotetext{
30 Broward County v. Janis Development Corporation (1975, Fla App D4) 311 So. 2d 371.

${ }^{31}$ Contractors and Builders Association of Pinellas County v. City of Dunedin (1976, Fla) 329 So. 2d 314; Hollywood, Inc. v. Broward County (1983 Fla App D4) 431 So. 2d 606; Town of Longboat Key v. Lands End (1983, Fla App D2) 433 So. 2d 574; Home Builders and Contractors Association of Palm Beach County, Inc. v. Board of County Commissioners of Palm Beach County (1983, Fla App D4) 446 So. 2d 140.
} 
- The fee to be charged may not exceed the reasonable cost to the system of absorbing the new users.

- The fees must be reserved for the purpose for which they are charged.

- The fees must actually be used for the designated purpose and used in an area that will directly benefit the development that paid the fees. ${ }^{32}$

In Florida and other states, the impact fee program of a local government must be consistent with its capital improvements plan.

A U.S. Supreme Court case established the "rational nexus" test, in which there must be a specific causal link between the need for additional facilities and the growth generated by the new development. In addition, a sufficient benefit from the exaction must accrue to those paying the costs. ${ }^{33}$ In a later case, the U.S. Supreme Court further clarified the rational nexus test by adding the requirement that exactions should bear a "rough proportionality" between the exaction and the impact of the proposed development. ${ }^{34}$ The calculations in impact fee programs to set fee rates accomplish this.

Impact fees can be arranged as flat fees, variable fees and negotiated fees. In programs nationwide, they can also be called a variety of names, such as infrastructure fees, system development charges, capital facility fees, building occupancy taxes, and connection fees. Impact fees for transportation have almost exclusively been used for road improvements but this may begin to change. Included below are the few cases found where there was some provision for the use of impact fees for transit improvements.

Problems with impact fees in programs nationwide have included the lack of reliable data on which to calculate demand for the public service, poor procedures to collect the data, the cost of data collection and issues regarding special uses. Impact fees must also be limited to use in a particularly defined geographic area and funds must be spent within a certain time period. Impact fees cannot be used for the elimination of existing deficiencies and cannot be used for operations or maintenance costs, based on the rational nexus test. An advantage of impact fees is that they can be used as a mechanism for raising funds from land developers for off-site improvements.

In some programs, voluntary donation of land is accepted in lieu of an impact fee. In this case, voluntary donation of property by an owner/developer should be property that is needed to accomplish the local work program. If it is not, then local government is giving an impact fee credit to the owner for land that is not needed in addition to taking away from the money or land otherwise obtained for a necessary project in the

\footnotetext{
${ }^{32}$ Case summary by Eric Damian Kelly, FAICP, "A Historic and Legal Perspective on Development Exactions," introduction to Transportation Impact Fees and Excise Taxes: A Survey of 16 Jurisdictions. Prepared by Connie B. Cooper. Prepared for the American Planning Association, Planning Advisory Service, Report No. 493. pp 2-3.

${ }^{33}$ Nollan v. California Coastal Commission, 483 U.S. 825 (1987).

${ }^{34}$ Dolan v. City of Tigard, 114 S. Ct. 2309 (1994).
} 
work program. A determination of creditable land donation should be based on whether it is located on the same site as the development and on what percentage of the donated land is usable by the general public. Transferability of credits should not be allowed beyond the impact fee zone.

The key for impact fees to work is for developers to have an up front idea of what the costs will be and the fee must directly benefit the project. Municipalities should establish mutual goals with developers. Municipalities must not change program rules that would inadvertently make it easier for the developer's competition.

\section{Hillsborough County, Florida}

Hillsborough County is one of the few local governments in Florida that generates funds for public bus transit capital facilities, through its roadway impact fee. In this case, the land developer pays a fee that is reflective of the entire transportation impact from the development. The fee is then allocated across modes based upon current mode share. The existing transit mode share, on the order of from one to three percent, comes from estimates from U.S. Census data.

\section{Orlando, Florida}

The impact fees used by Orlando are road impact fees and cannot be used for transit funding; however, the Transportation Impact Fee Ordinance allows the city to issue credits against impact fees to developers for contributions to public transportationrelated improvements such as providing land for bus stops or building transit shelters.

The credit could be in an amount equal to:

1. the cost of non-site related improvements to the major road network (including on-site and site adjacent arterial roads and major collectors to the extent such improvements are in excess of or in addition to the site related improvements), or;

2. the contribution of land, money or service for non-site related improvements to the major road network (including on-site and site adjacent arterial roads and major collectors to the extent such improvements are in excess of or in addition to the site related improvements), or;

3. non-site related roadway improvements previously contributed, paid for or committed to by the applicant or his predecessor in interest. ${ }^{35}$

${ }^{35}$ Orlando City Code, Chapter 56, Road Impact Fee. http://www.municode.com 
These credits against impact fees have been used infrequently, possibly because ordinance language may be too vague or that developers may not be aware of the credits. $^{36}$

\section{Broward County, Florida}

The Broward County Mass Transit bus system connects all municipalities and interconnects with Palm Beach and Dade counties. Transit impact fees are assessed instead of road impact fees in some cases, generally in an area in eastern Broward County that is designated as urban infill. Transit impact fees can be used for any capital costs that are outlined in the Transit Development Plan (TDP), such as transit centers, buses, shelters, information kiosks, Intelligent Transportation System (ITS) improvements, and bus bays. The transit impact fee has been in effect since 1996.

The Broward County Land Development Code contains the specifications for the transit impact fee. ${ }^{37}$ Development permitting requires approval for any development within an area designated on the Broward County Land Use Plan for urban infill, urban redevelopment or downtown revitalization. Approval requirements include a finding at the time the development permit is issued that the adequacy of transit service standards have been satisfied.

If the costs of the adopted Broward County Transit Development Plan (TDP) are not fully funded, then the specific capital improvements within the TDP which enhance transit service within each designated area shall be identified. The application shall be granted with the express condition that the applicant deposit money in a "transit account" in an amount calculated according to a fee schedule that is updated every October 1 . The schedule provides the required fee per unit of development for a variety of different types of developments. The transit impact fee applies only to development applications that require platting and are located in the urban infill area within the County. As a result, the transit impact fee has not raised as much money as it otherwise could.

\section{Montgomery County, Maryland}

In Montgomery County, impact fees are called development impact taxes. Recently the County Council proposed an amendment to the development impact tax ordinance. If approved, the changes would become effective on July 1, 2002. The proposed amended ordinance revises the eligible projects that can be funded with impact fees. These include the addition of road capacity that improves transit service such as bus

\footnotetext{
${ }^{36}$ Pedro Leon, Transportation Capital Administrator, City of Orlando Transportation Planning Bureau, phone conversation, 10/01/01.

${ }^{37}$ Broward County Land Development Code, Chapter 5, Article IX, Section 5-182, Subsection U.
} 
lanes, new or expanded park-and-ride lots, new buses (not replacement buses), new bus shelters (not replacement shelters), and sidewalks. ${ }^{38}$ The county does not assess impact fees on government buildings, moderately priced housing, or any new development within a short walk to a Metro station.

\section{Portland, Oregon}

The Transportation System Development Charges (SDC) Ordinance ${ }^{39}$ was adopted in Portland in 1997, pursuant to the Oregon Systems Development Act. Portland's ordinance provides for the collection of fees, based on a rate study. ${ }^{40}$ SDCs are multimodal impact fees and are one-time fees paid by new development to pay the government for capital costs of public facilities.

Eligible modes include motor vehicle, transit, bicycle, and pedestrian improvements. Eligible improvements include new through lanes for vehicular, transit, and bicycle use, bridges, rights-of-way acquisition, intersection and signal improvements, landscaping, walkway, bike paths, and design/engineering costs. Characteristic of impact fees, funds cannot be used for maintenance or elimination of existing capacity deficiencies.

System development charges (SDCs) are based on a property's projected trips for a new use less the trip generation rate of the previous use. If the calculation is within 15 percent, no SDC is required. Modal splits are also computed among vehicular, transit, and nonmotorized trips. Credits are provided for transit-oriented development. In order to promote the use of transit, Portland encourages transit-oriented development by discounting SDCs for development that is transit oriented. ${ }^{41}$

The City Comprehensive Plan identified 36 multi-modal capacity improvement projects for SDC funding. Total cost for these projects was approximately $\$ 95.9$ million. Each project was analyzed to determine the portion of its cost that was attributable to three modes of travel: motorized (automobile, truck, and motorcycle), transit (rail and bus), and non-motorized (pedestrian and bicycle). Allocation of project costs among the three modes was achieved by using the following process:

- Separate the direct costs of each mode from costs that are common to all modes of travel.

- Identify the direct costs of non-motorized facilities and subtract this amount from all other direct costs.

\footnotetext{
38 Proposed amendments to the Montgomery County Code. Chapter 52, Taxation.

${ }^{39}$ City of Portland Code, Title 17 Public Improvements, Chapter 17.15 Transportation System Development Charge.

40 Transportation System Development Charges Rate Study, Henderson, Young \& Company, 1997.

${ }^{41}$ Connie B. Cooper, Transportation Impact Fees and Excise Taxes; A Survey of 16 Jurisdictions. American Planning Association, Planning Advisory Service, Report No. 493, p 35.
} 
- Allocate the remaining direct costs between transit and motorized modes. The transit portion was determined by comparing the transit passengers along the project route to the total of all persons ("passengers") moving on the same route in all motor vehicles. The motorized portion of direct cost was the remainder (after subtracting non-motorized costs).

- Divide the direct cost of each mode by the total direct cost of all three modes to identify the relative distribution of project costs among modes. The resulting percentage for each mode's direct cost was used to allocate the common costs among the three modes. ${ }^{42}$

Each mode of travel was analyzed separately to determine the "through" trips (trips that begin and end outside the city limits) on each project in the SDC capital improvement program. For transit travel, transit trip matrices (from the regional travel model) were created using the trip origins and destinations of each project's corresponding geographic area. Once the "through" trip percentages were calculated for each project (or project group), the percent of "non-through" trips was calculated.

Other aspects of the SDC rate calculation process included finding the project cost attributable to SDC, the cost per new trip for each mode, and trips generated by various types of development. Finally, the SDC rate for each type of land use was calculated by multiplying the number of trips by the percent of trips on the mode of travel. The result was multiplied by the cost per new trip for the mode of travel.

The SDC program took effect on October 20, 1997, after many information meetings and debate which led to adjustments to the program, such as the discount for transit oriented development and exemptions for low-income housing. The implementation issues include internal miscommunication regarding SDC charges and exemptions, delay in collecting revenue due to a payment deferment option, lack of public awareness of the new ordinance, difficulty understanding the system of credits, and reduced revenue due to exemptions.

\section{Developments of Regional Impact}

It is important to examine developments of regional impact (DRI) in this report because DRIs usually represent the largest developments and as such, have the greater potential impact on land development patterns and the opportunity to influence the development of the transportation system. The development of regional impact review process is concerned with identifying multi-jurisdictional impacts of development and

\footnotetext{
${ }^{42}$ Paul Shirey and Donald R. Samdahl, "Multimodal Impact Fees", Transportation, Land Use, and Air Quality—Making the Connection, Conference Proceedings May 17-20, 1998 (Reston, VA: American Society of Civil Engineers, 1998) 500-503.
} 
establishing mitigative conditions under which building activity may be permitted to proceed. The structured DRI review process facilitates capital improvements planning.

A Florida Development of Regional Impact (DRI) is any development that, because of its character, magnitude, or location would have a substantial effect upon the health, safety, or welfare of citizens of more than one county. ${ }^{43}$ There are different types of DRIs, including the following.

- Areawide DRIs, in which there are two or more development projects represented by separate property owners

- Downtown DRIs

- DRI Master Plan, in which construction is in phases over an extended period of time

DRIs are established by Chapter 380, F.S., which authorizes the Florida Department of Community Affairs to develop land and water management policies to guide local decisions relating to growth and development. DRIs are implemented by rules in the Florida Administrative Code, Chapter 9J-2.

The DRI designation of a land development proposal initiates a review process, in which the regional planning council, the state and other agencies have an opportunity to provide recommendations to the local government in the drafting of conditions attached to a local government development order for assuring that regional impacts have been properly addressed. ${ }^{44}$ The regional impact review includes the documentation of impacts upon transportation as part of an Application for Development Approval (ADA), which must be approved by the Department of Community Affairs.

Transit service is addressed in the ADA question, "What provisions, including but not limited to sidewalks, bicycle paths, internal shuttles, ridesharing, and public transit, will be made for the movement of people by means other than private automobile? Refer to internal design, site planning, parking provisions, location, etc."

The end result of the DRI process is a resolution passed by the host municipality, rendering a development order (DO) in response to an Application for Development Approval submitted for a project that has been determined to be a development of regional impact. The DO must be consistent with Chapter 380, F.S., Rule 9J-2 F.A.C., the local government comprehensive plan, the strategic regional policy plan, and the state comprehensive plan.

\footnotetext{
43 Chapter 380.06, F.S.

${ }^{44}$ A local government development order is any order granting, denying, or granting with conditions, an application for a development permit, whereas a development permit includes any building permit, zoning permit, plat approval, or rezoning, certification, variance, or other action having the effect of permitting development activity to proceed, as defined in Chapter 380, F.S.
} 
Fourteen types of projects may be DRIs if they exceed specific size thresholds. These development types include airports, hospitals, and hotels, as well as industrial, office, retail, residential, and multi-use developments. Thresholds for determining DRI status include building square footage, acreage, and parking requirements.

If a project is determined to have a transportation impact, then a separate traffic methodology meeting must be held. This allows the regional planning council, the Florida Department of Transportation, the Florida Department of Community Affairs (DCA), the local government, and the applicant to decide on a mutually acceptable methodology for identifying a project's transportation impacts, thus saving time and simplifying the process.

Rule 9J-2.045(7)(a)1-5, Florida Administrative Code, lists the following measures that can be used to mitigate transportation impacts and which reasonably assure that public transportation facilities will be constructed and made available when needed to accommodate the impacts of the proposed development, consistent with Chapters 163 and 380, F.S.:

- scheduling of facility improvements

- alternative concurrency provisions

- proportionate share payments for roadway improvements based upon peak hour roadway trips generated.

- level of service monitoring with binding commitments for needed improvements

- a combination of the above mitigation measures, OR the provision for capital facilities for mass transit [e.g. buses for fixed route service, vehicles for vanpool or ride share programs]

Through the DRI process, RPCs in Florida have recommended to local governments a number of conditions as part of a DRI development order, that the developer:

- consult with the transit agency to determine the transit related needs to serve the project and coordinate with any plans to extend transit to the project;

- be financially responsible for any implementation of on-site amenities;

- establish a transportation systems management plan that includes use of bus transit as a means to reduce project-related p.m. peak hour automobile trips;

- coordinate with the city to promote transportation demand management strategies; and,

- when transit is already available to the site, build bus turnout bays and reasonably sized bus shelters along public roadways to serve the development, as required by the local government, or provide the transit agency with the funds to do it. 
For approving a development order that requires developer exaction, the local government must comply with Paragraphs 380.06(15)(d), (e), and Subsection 380.06(16), Florida Statutes, which are similar to requirements for impact fees.

The Florida Statutes state that DRI developments must pay their proportionate share only if non-DRIs are required to pay also. The law further states that developers cannot be charged twice for the same impact. The key for a land developer to fund transit is to demonstrate that impacts would be mitigated by doing so. The existing DRI process instructs the developer to use professionally accepted methods for assessing level of service (LOS). The tools of analysis available for determining level of service are mode specific. Most commonly in use is the Highway Capacity Manual method for determining roadway level of service. Recommended development order conditions regarding bus transit generally assume that the local government or local transit provider will run a bus route past the development site, if they are not already doing so.

\section{FDOT Procedures for Site Impact Analysis}

Proposed developments that do not meet the size thresholds constituting a DRI do not require site impact review by FDOT.

The FDOT procedures for site impact analysis is a process that is specifically geared toward determining a new development's roadway traffic impacts upon the State Highway System and the Florida Interstate Highway System. Most FDOT activities relating to site impact assessment originate from amendments to the future land use map (FLUM) of the comprehensive plan and amendments to the comprehensive plan due to a proposed development of regional impact (DRI).

The estimated traffic impact is the basis for determining the developer's fair share cost in contributing to roadway improvements that are necessary to maintaining roadway level of service. Considerations about transit usually only arise in relation to the ability of alternative modes to serve some of the new trips generated by the development, lessening the impact to roadway level of service.

According to FDOT's Standard Site Impact Procedures, there is a process composed of several steps, conducted in this order:

1. Methodology Development

2. Existing Conditions Analysis

3. Background Traffic

4. Trip Generation

5. Trip Distribution

6. Mode Split 


\section{Assignment \\ 8. Future Conditions Analysis \\ 9. Mitigation Analysis, if necessary \\ 10. Site Access, Circulation and Parking \\ 11. Review and Permitting}

It is the applicant who proposes a methodology for reviewers' concurrence for determining site impact. The study area, also called the area of influence, is typically estimated using professional judgment and then refined during the study process. The DCA rule for DRIs requires that the study area include all facilities where traffic generated by the proposed development is equivalent to 5 percent of the maximum service volume at the LOS standard for the facility.

The methodology for determining the developer's fair share for funding of mitigation improvements is identified in the Methodology Development (Step 1) phase of the impact analysis. The fair share is determined in relationship to the number of trips generated by the development and the capacities on an affected roadway segment.

Step 2, the Existing Conditions Analysis, includes a review of existing transit service and transit ridership.

It is interesting to note that Step 4, Trip Generation, is a separate step conducted before the estimation of person trips. Trip generation differentiates trips as motor vehicle movements and it is considered to be the most critical stage in the site impact analysis. The amount of travel that uses modes other than automobiles is estimated using regional and local guidelines based upon existing transit usage. As a result, 3 to 5 percent is considered a maximum realistic share of travel for modes other than automobiles.

Step 6, mode split, is the analysis portion that estimates the amount of travel in person trips that will use the various modes available to the site.

References to transit appear again in Step 9, the mitigation analysis, in which the measures proposed must clearly demonstrate that they contribute to reducing traffic congestion along facilities where LOS has been made unacceptable upon the addition of the new development. The mitigation analysis includes a plan that details system improvements necessary with the phasing of the project and identifies the responsible party for implementing the improvements. Improvements typically include some combination of physical or operational changes to the roadway facilities, transportation demand management strategies, and fair share contributions by the developer.

Under Mitigation Analysis, various examples of mitigation measures are listed, including construction of new facilities and addition of general-use lanes. Where the construction of new facilities are considered, enhancements for the use of transit, such as geometric 
and operational improvements to accommodate bus travel are encouraged. Other encouraged mitigation measures include enhancements for the use of transit, such as the construction of park and ride lots, the construction of bus shelters and turn-out bays. The measures also include high occupancy vehicle (HOV) treatments such as the construction of HOV access ramps and the implementation of HOV priority lanes. Public transit operational improvements are other available mitigation measures. These improvements include new or modified service routes and employer subsidized transit. This measure can be used if it can be demonstrated that the necessary agreements are in place with the local transit agency and that the strategy can be demonstrated to cause a mode split shift toward transit. Transportation demand management techniques, such as providing transit subsidies, are recognized as having potential to reduce site traffic. A monitoring plan is usually put in place to measure effectiveness.

The mitigation analysis demonstrates that the proposed improvements will result in an acceptable operating condition along the roadway. The calculation of the proportionate share contribution is based upon a formula, as provided in the Florida Administrative Code. The final fee and mitigation fee considered is typically negotiated among the applicant, local governments, regional planning councils and FDOT if state highway improvements are involved.

\section{A Summary of Stipulated Conditions Relating to Bus Transit}

All RPCs in Florida were contacted with the request to provide best examples of RPC recommendations for the provision of bus service. The list below is a synthesis of conditions that RPCs in Florida have recommended to local governments as part of a DRI development order. These include recommendations that the developer do the following.

- Consult with the transit agency to determine the transit related needs to serve the project and coordinate with any plans to extend transit to the project.

- Be financially responsible for any implementation of on-site amenities.

- Establish a transportation systems management plan that includes use of bus transit as a means to reduce project-related p.m. peak hour automobile trips.

- Coordinate with the city to promote transportation demand management strategies.

- When transit is already available to the site, build bus turnout bays and reasonably-sized bus shelters along public roadways to serve the development, as required by the local government, or provide the transit agency with the funds to do so.

- Subsidize a bus route to a new mall and provide bus drop-off at the front entrance.

- Provide a parcel within the development for a transit stop that can accommodate multiple buses at one time. 
- In public gathering places, provide a place where transit information can be prominently displayed.

- Encourage tenants and owners within the employment centers to provide preferential parking for vanpools/carpools.

- Disseminate information to tenants and residents about local ridesharing programs.

- Some period of time after the issuance of the development order, propose transit-related actions, facilities, and sites to the municipality and transit agency.

- Consider paying the cost for an additional bus route to the DRI or increased frequency on existing routes during later phases of construction.

- Maximize access by interconnecting parcels within the development and providing road linkages to the local street system.

- Provide park and ride spaces proximate to a multi-bus transit stop, either in conjunction with commercial development or by purchase of property.

- Designate a part-time ride share coordinator to distribute transit information.

- Include transit-oriented design (TOD) features into the project design, as specified by a transit agency design manual, such as covered pedestrian walkways linking buildings to transit stops.

- Establish a transportation management association to implement trip reduction programs within the DRI.

- Provide sidewalk access between transit stops and nearby residential and commercial development.

Information from two other development orders is provided here, which may provide ideas for how transit can be accommodated.

\section{Alachua County, Florida}

The Springhills DRI Development Order (DO) language found in Alachua County Resolution 99-73 is illustrative of the kinds of conditions regarding provision for bus transit capital facilities and operation costs that can be included in a DO. Springhills is a mixed-use development that is located in the unincorporated area of Alachua County, but within the Gainesville Urban Area. It is situated on all four quadrants of the intersection of SR 22 (NW 39 ${ }^{\text {th }}$ Ave) and I-75. The development is to be in four phases, with the first two (retail commercial) already completed. The residential, single and multi-family, is the next phase.

The development order contains the following.

- In the interest of safety, and to promote alternative forms of transportation, the Applicant shall provide a plan for an on-site system of bikeways and pedestrian circulation for all of Phase I. 
- Notwithstanding the arrangements able to be achieved within the Springhills TMA, the Applicant shall coordinate with the Gainesville Regional Transit Service in Alachua County for the expansion of transit routes to serve the Springhills DRI and provide for integration with existing transit service in or adjacent to the DRI study area and the regional transit service area prior to the initiation of Phase II.

- Prior to Phase II construction, the developer will construct a covered bus shelter to serve the new bus route that will access the DRI.

- Bicycle lockers or bicycle racks, transit passenger shelters and transit parking bays, consistent with Alachua County Land Development Regulations and RTS policies and requirements, shall be constructed to augment and facilitate the operations of transit service to the site in Phase II and in all future phases in conjunction with the extension of transit service. Transit pull-out bays and transit shelters, and their location as required by Alachua County Public Works Department and Department of Growth Management and the Applicant's trip reduction strategies shall be constructed by the applicant within the site boundary following approval by the Alachua County Public Works Department. The location of transit facilities shall be approved by the transit provider in cooperation with Alachua County. The Applicant shall consult with Gainesville Regional Transit System in order to determine the appropriate number and location of pull-out bays and transit shelters. The Applicant shall promote and encourage variable work hours and flextime participation by on-site employers.

- Sidewalks shall be constructed along both sides of all collector and arterial internal roadways, where feasible.

- Sidewalk access will also be provided between transit stops and nearby residential and commercial development.

- During Phase III, a possible mitigative measure includes an additional RTS bus route to the area or increased frequency on existing routes.

- The annual report shall also document mass transit modifications, bicycle/pedestrian modifications, and any other TSM/TDM strategies undertaken to date to reduce single occupant vehicle (SOV) trips, and changes in mass transit frequency and level of service as well as bicycle/pedestrian levels of service, when such levels of service are adopted by the Board of County Commissioners. The Annual Monitoring Report (AMR) shall evaluate and recommend mitigative measures involving/including local street networks, transit, bicycle/pedestrian facilities, and service to address any transportation system capacity deficiencies identified in the report for the year being monitored. 
- The AMR shall specifically investigate and make recommendations on non-auto modifications (including, but not limited to, park and ride lots, mass transit, bicycle, and pedestrian enhancements), which will help reduce SOV trips.

- To reduce traffic impact on the regional roadway network, the AMR shall investigate opportunities for new roadway facilities to provide and promote route choice.

- Trip credits will be granted for mitigative measures listed, e.g. mass transit, park and ride lots, by Alachua County Dept. of Public Works based on documentation of the mitigative measures to be undertaken by the Applicant/Owner and supported by appropriate data.

- In addition, through the study and/or Springhills Transportation Management Association (TMA), the Applicant shall make a good faith effort to coordinate transit service and other trip reduction strategies with Santa Fe Community College and AvMed Health Services.

- If the annual monitoring report indicates that the trip reduction program is operating more effectively than the model used with the revised transportation impact study estimated, then additional trip reduction credits may be granted.

\section{Orlando, Florida}

Florida Hospital contributes $\$ 25,000$ annually for transit services as a requirement of its DRI approval. Florida Hospital is the largest private, not-for-profit hospital and second largest hospital overall in Florida. It is the third largest employer in the Central Florida area and one of the largest in the Orlando area. The hospital is one of the nation's leading cardiac intensive care/open heart centers.

DRIs are usually a pay-as-you-go process. Normally, there are multiple phases of development during which each impact must be assessed on an ongoing basis. This DRI was not typical. The hospital wanted a "higher level of certainty" (of the costs) because of the nature of the healthcare business. Therefore, they opted for negotiated annual payments. Florida Hospital's development order contained the following.

- Transit and current ridesharing information must be displayed in all public gathering areas, in employment centers, and in commercial center areas on the hospital property. A staff member must be designated as an Employee Transportation Coordinator (ETC) and must coordinate Transportation Demand Management programs in cooperation with LYNX.

- Florida Hospital agrees to pay for the construction of six (6) bus shelters within the planning area. They are also responsible for the maintenance of 
the shelters. Bus shelters, bus stops, and amenities are designed in cooperation with LYNX. The City Transportation Engineer and LYNX will determine where transit bays are needed within and adjacent to the planning area.

- If additional land owned by the Developer within the Property is necessary for bus stops beyond that which can be accommodated within the existing rightof-way, then this land shall be provided by the Developer at no cost to the City or other applicable government agency.

- The Developer shall become actively involved with van pools and joint ventures with public agencies to offer mass transit facilities and services. The hospital must provide a fifty percent $(50 \%)$ transit fare discount for employees.

- The hospital must continue to be an "active and financially supportive" member of the Downtown Orlando Transportation Management Association (DOTMA). Either through DOTMA or on their own, the hospital must develop a TDM program. The TDM program was subject to the review by the City prior to the issuance of a Certificate of Occupancy.

- The TDM program is to consider "at a minimum the following": parking management provisions for carpools and vanpools, publicity for transit and ridesharing information, work hour adjustments (compressed week, flextime), telecommuting where possible, showers and bicycle lockers, and daycare facilities.

- The hospital was required to make a one time payment to the City towards mass transit system improvements on the two (2) routes serving the project. An annual contribution was also required. These were specified in the agreement between the City and the hospital. The agreement stipulated the following: $\$ 379,481$ for the one time payment, and $\$ 25,000$ annually. The annual contribution cannot be increased.

\section{Observations}

This section summarized the existing use of non-regulatory and regulatory tools used by local governments in the State of Florida and elsewhere in the nation.

This investigation found that non-regulatory approaches are not frequently used alone unless there is an extraordinary opportunity of mutual gain, as found in a joint development opportunity. The vast majority of these cases involving private sector land developer contributions concern light rail rather than public bus transit.

The successes experienced by local governments and transit agencies, in securing private sector land developer participation, appear to have relied strongly upon a few key regulatory measures. In Florida, these measures include the local government comprehensive planning process and requirements of the land development code, in 
the form of zoning, transportation concurrency exception areas, and impact fees. The development review process for developments of regional impact provides further opportunity for the host local government to establish conditions in which land developers provide for transit facilities and operations.

It is most commonly the case that a land development code contains provisions that land development provide for access to transit, mainly through connective sidewalks and land for a bus stop. The amenity most frequently provided is bus shelters. In a few instances, mainly in Hillsborough and Broward counties, funds have been provided for a limited amount of time, usually 3 years or less, to operate bus service along a route extension or in the form of shuttle service that connects to a standard bus route.

The U.S. Supreme Court case law and the Florida Statutes clearly restrict the application of impact fees to protect the private sector. Land developers only must pay a fee representing the impact of the development on the transportation system. It is challenging to express that impact in the form of a transit mode share, especially in areas where transit service is nonexistent or infrequent.

Transportation concurrency has been traditionally applied to mean roadway concurrency. The application of concurrency relies primarily on processes and measures of level of service that emphasize highway travel. Transit usually enters the discussion only if it has been determined that roadway improvements alone cannot raise the level of service to the adopted standard. There is interest in transit usually to the extent that it can be proven that transit service will mitigate traffic impacts.

Localities, such as Orlando, where there seem to be more promising opportunities to engage private sector land developer participation in providing for public bus transit capital facilities or operations, appear to rely upon:

- strong policies in the comprehensive plan;

- land development code language that effectively implements the comprehensive plan;

- information for both land developers and local governments to use, such as urban design manuals and customer amenities manuals, which takes the guesswork out of what is desired by the transit agency and expected of the land developer; and

- a host local government that places a priority on transit service and advocates effectively on behalf of public transit development.

The next section looks at future possibilities for strengthening the options for local governments to engage private sector land developer participation in public bus system development. 


\section{Future Considerations for Interactions with Developers}

The previous section in this report covered examples of both non-regulatory and regulatory approaches that have been used in Florida and other states to engage private sector participation to contribute toward the costs of public bus transit capital facilities and operations. This last section presents examples of other mechanisms that have been used in other states that could be considered for use in Florida. In addition, there are a few examples of mechanisms in the proposal stages, such as Broward County's proposed transit-oriented concurrency system and the City of Boca Raton's proposed trip reduction ordinance, which have good potential for engaging land developer participation. There is also an example provided here of transit overlay zones, which are currently used in Miami-Dade County but for rail station areas only. Transit overlay zones could be used for public bus facilities as well.

As with the previous section, the discussion begins with non-regulatory approaches, then moves on to regulatory approaches.

\section{Non-Regulatory Approaches}

\section{Employment Park Foundations}

The concept of an employment park foundation is presented here for future consideration. There may be similar employment parks or foundations in Florida. Companies located within employment parks may depend upon transportation improvements to their sites and so may be willing to fund transit improvements in the future.

\section{Research Triangle Park, North Carolina}

The Research Triangle Park Foundation, a private non-profit foundation that develops and markets the Research Triangle Park, is made up of all the companies who bought land within the Park (IBM, Nortel, Cisco, Glaxo and others). The Research Triangle Park Foundation raises funds through the selling and leasing of land within the Park. ${ }^{45}$

The Research Triangle Park, located between the cities of Raleigh and Cary, is a bustling center of high-tech employment. As traffic congestion has increased on Davis Drive, the main roadway through the Park, the need for transportation improvements has also increased. The North Carolina Department of Transportation (NCDOT) did not have the funds for improvements for Davis Drive in their seven-year Transportation Improvement Program. The State has a legislative requirement for the equitable

\footnotetext{
${ }^{45}$ Conversations with Liz Rooks, Transportation Manager, RTP Foundation and Glen Lang, Mayor of Cary.
} 
distribution of transportation funds to its 100 counties through the use of a formula that tends to favor economically distressed areas of the state while being less able to respond to rapidly growing areas.

In the spring of 2000, the Research Triangle Park Foundation entered into a publicprivate agreement with NCDOT and the Town of Cary, which calls for Cary to contribute funds to cover the cost of road improvements along the portion of Davis Drive within their jurisdiction. The Foundation will contribute the funds to cover the cost of improvements on the portion of Davis Drive within Research Triangle Park, and NCDOT will cover the cost of road improvements on the remainder of Davis Drive. Although this example involves a partnership to pay for road improvements, it also serves as a model that could be applied to transit improvements as well as services.

\section{Cost Sharing Programs}

In the example below, the "private partner" is actually a public university, not a private developer, but it was included in this report because it illustrates how public transit can harness funds from a different revenue stream, in this case, a department of education. The concept would also appear to be transferable to a case in which a transit agency serves a private university or college.

In Florida, campuses of State universities are subject to campus master planning requirements as well as transportation concurrency. As new campus construction and development tries to keep pace with ever-growing enrollment rosters, administrators struggle to address campus transportation impacts upon the adjacent highway network. The example from North Carolina below offers an alternative arrangement in which the operating costs of public transit are supported by the university.

\section{Chapel Hill, North Carolina}

Chapel Hill Transit operates the transit system in Chapel Hill with two financial partners, the Town of Carrboro and the University of North Carolina (UNC) at Chapel Hill. Chapel Hill and Carrboro are contiguous municipalities, and the transit agency provides service in these two areas in addition to the UNC campus. The financial assessments of this three-way partnership are based on population: the population of each city plus the total population of UNC (faculty, staff, and students). Currently, Chapel Hill's share is approximately 45 percent, Carrboro's is 16 percent, and UNC's is 39 percent.

The current agreement stipulates that if one of the partners requests a new service such as a new bus route, that partner is responsible for paying for the new service in full for one year. At the end of the first year, if the route's ridership has met service standards, then the route is established and all partners must share in the additional 
cost. However, if ridership is below service standards, the requesting partner must continue to fund the service in full if it is to continue. Currently, UNC funds all university services, including circulators and shuttles, in full and also shares in the population based assessment for the cost of the total service. The university pays the transit agency $\$ 10$ per service hour. Beginning in January 2002, all transit service to the university became fare free, funded by the university.

\section{Public Pressure}

A third example below is another case of voluntary contributions by the owner/developer but only as a result of public pressure to provide transportation solutions. This speaks to the potential power and influence of an educated and wellorganized host community.

This may also point to the value to local government of using available tools to help educate citizens. One example of this is the establishment of a transportation management association (TMA). In Tampa, Florida, the University North Transportation Initiative (UNTI) is a unique partnership of local government representatives, large employers and residential neighborhood leaders. The membership has become increasingly supportive of public transit as a result of the learning process that comes from active involvement in a TMA.

\section{Portland, Oregon}

A concentration of medical institutions on Marquam Hill in the City of Portland needed to respond to traffic congestion problems in the area. In particular, the Oregon Health Sciences University (OHSU), which constitutes over 70 percent of the employment population, faced a major space problem and needed to expand. There is just one main access road that leads into and out of Marquam Hill, which also includes a residential population organized with a strong neighborhood association. Because of community pressure about traffic congestion, the City required the medical institutions to mitigate traffic problems before starting new construction. OHSU recognized that the neighborhood association would have testified against the OHSU expansion and the City would not have given OHSU a permit to expand without a credible plan to reduce traffic on the Hill.

In response, the medical institutions voluntarily decided to enter into the Marquam Hill Partnership with the City of Portland and the transit agency, Portland Tri-Met, to provide express bus service directly to the Hill, paying for 70 percent of the operating costs of four express bus routes. Tri-Met paid the other 30 percent of the operating costs to maintain public access to the bus service. 


\section{Low Income Housing}

A discussion of affordable housing is provided here for two reasons. One, affordable housing ventures can be profitable to land developers. Two, there is reason to consider that potential changes in the developer selection application process of some housing programs could rate the provision of transit services and facilities as a higher priority. In this way, developers could be more strongly encouraged to incorporate transit service and amenities into their development proposals for affordable housing.

Since the 1934 creation of the Federal Housing Administration, the United States government has sought to extend opportunities for home ownership and rental housing to those unable to afford it on their own. To utilize the three federally authorized programs that seek to provide low-income housing, a Housing Finance Agency has been established in each of the nation's fifty states, the District of Columbia, Puerto Rico, and the Virgin Islands. These programs are the Mortgage Revenue Bond (MRB) program, the Low Income Housing Tax Credit program (Housing Credit), and the HOME Investment Partnerships Program (HOME). Through these programs, the federal, state, and local governments form a partnership with organizations in the private sector to finance and build low income housing initiatives.

Chapter 420.502(7), F.S. created Florida's housing finance agency, the Housing Finance Corporation (FHFC). FHFC is affiliated with the Department of Community Affairs (DCA), which has performance oversight; however, the FHFC is administratively distinct from the DCA. The FHFC operates much like a private sector entity, although it is a public corporation, and is managed by an executive director appointed by the DCA. The FHFC issues bonds to generate funds for housing construction, manages Statefunded programs such as loan guarantees, and provides grants to local governments for housing construction. The corporation concentrates on funding single-family home ownership programs and multi-family (rental apartment) loan programs for individuals with low- to moderate-income levels.

Private land developers find affordable housing ventures attractive for several reasons. For instance, under the Housing Credits program, developers receive a 10-year federal income tax dollar-for-dollar reduction in exchange for cash infusions for new construction and restoration projects. The HOME program provides mortgage loans to developers that are non-amortized and have a simple interest rate of 0 percent for nonprofit organizations and 3 percent for for-profit organizations. Interest repayment is only during the term of the loan and loan terms are 15 years for rehabilitation and 20 years for new construction. Additionally, low-income rental properties fill up quickly and remain at full occupancy rates due to the high demand. These developments are profitable and are driven by market economics. 


\section{Hillsborough County, Florida}

In Hillsborough County, the Housing Finance Authority, assisted by the Community Improvement Department, administers the Multifamily Mortgage Revenue Bonds (MMRB) Program, State Apartment Incentives Loan (SAIL) Program, Housing Credit (HC) Program, and other housing programs that provide incentives to the private sector to develop affordable housing. MMRB and HC are federal programs; SAIL is a state program that can be used in conjunction with other state and federal programs.

The developer selection process requires the developer to agree to set aside commitments (depending on the program and type of development). The developer is also required to provide certain construction features. For instance, for any Multifamily Mortgage Revenue Bond (MMRB) project, such as new construction, rehabilitation of existing development, elderly development, and non-elderly development, the following items are required.

- air conditioning in all units

- dishwasher (in all new construction)

- garbage disposal (in all new construction)

- cable TV hook-up

- minimum square footage of living space

- full sized appliances

- a bathtub

Since developer selection is a competitive process, additional features or amenities may be chosen that are rated on a point basis. Applicants are ranked in order of the total points assigned according to the amenities that are selected. Loan amounts are assigned in order of this ranking. For example, under an MMRB project for new construction for non-elderly developments, the developer must select items totaling 25 points. The developer could choose window treatments (3 points), 30-year expected life roofing ( 5 points), ceramic tile bathroom floors ( 2 points), marble window sills ( 3 points), double compartment kitchen sink (1 point), or other amenities. Public transportation must be located within one-half mile of the property.

For elderly developments, the developer must select items totaling 16 points. All items are worth 2 points each, and all must be on-site and include hairdresser or barber shop, laundry facilities on every floor, and a library consisting of a minimum of 100 books and 5 magazine subscriptions. Public transportation must be located within 150 feet of the property or the developer can choose to provide private transportation.

There is some question whether the needs of affordable housing residents are being met with these developer choices, as influenced by the point rating system. It is often the case that when private transportation for elderly developments is the option chosen, the developer provides one van to serve a large population within the 
development, which can be inadequate. A bus stop that is one-half mile from someone's home is a burdensome distance and even more so during inclement weather or if the person has packages to carry or children to tend.

Since many low-income housing occupants are also transit users, the provision of transit amenities and better access to service could be a significant boon for them as well as for transit agencies. It is recommended that the application process for low income housing be reviewed to determine if it is possible to change the required features to include more accessible transit service and/or to change the rating scale of amenities to reward developers higher points for providing public bus transit access, capital facilities and service operations.

\section{Regulatory Approaches}

This investigation found some other regulatory approaches that a local government might find useful to consider in strengthening the means to engage private sector land developer participation in providing for public bus transit capital facilities or operations.

A discussion of regulatory approaches below includes overlay zoning, impact fees, trip reduction ordinances, special assessments, new approaches toward evaluating concurrency, and ideas to consider regarding the DRI process.

\section{Overlay Zoning}

An overlay zone provides for superimposing additional specified requirements onto a basic use zoning district. Where the standards of the overlay and the base zoning district differ or are in conflict, usually the stricter standard applies. A transit overlay district assigns controls that accommodate transit in addition to the basic requirements of the underlying zoning district. Such controls may require the provision of pedestrian walkways to access transit and the provision of transit stops and shelters.

Transit overlay zones are more typically associated with allowing high-intensity commercial and office development adjacent to rail stations, such as the overlay zone in Santa Clara County, California, which is associated with the Tasman East and Tasman West Light Rail Projects in San Jose. In the future, transit overlay zones may be useful in corridor planning for bus rapid transit.

\section{Miami-Dade County, Florida}

Miami-Dade County is an example of a transit overlay zone used in areas adjacent to light rail stations. In the future, Miami-Dade County is considering expanding it to cover the South Miami-Dade busway and possibly several other park-and-ride facilities. 
Miami-Dade County is a charter county and is comprised of an unincorporated area and 30 incorporated municipalities, each having its own government. Miami-Dade County's municipal code, Chapter 33-C, Fixed Guideway Rapid Transit System, Development Zone, provides for a Rapid Transit Zone that is in effect at MetroRail stations.

The original transit district was created in 1974 and wiped out all existing zoning. The philosophy applied to the overlay approach is that it is a work in progress, and has been changed many times. For example, the Dadeland North and Dadeland South subzones no longer exist and were replaced by a transit overlay zone for the entire Kendall area.

The Dadeland North and Dadeland South MetroRail stations are near one of the largest shopping malls in the nation and also located within the Rapid Transit Zone. The Dadeland North MetroRail station connects to eight Metrobus routes. Seven Metrobus routes connect with the Dadeland South MetroRail station, which also represents the south terminus of the County's heavy rail service.

In 1994, the Miami-Dade Board of County Commissioners approved the lease of a 9.2acre site at the Dadeland North MetroRail station. The project is called Dadeland Station, consisting of a three-phase mixed-use project that includes a transit plaza with 9,600 square feet of "transit convenience retail," in addition to 320,000 square feet of retail space. Hotel, office and residential uses are included for future phases. The County, which receives both guaranteed minimum rent and gross income from the project, will realize between $\$ 40$ million and $\$ 100$ million in new revenue over the term of the 99-year lease. Near the Dadeland South MetroRail station, there is the Datran Center, a privately owned development that leases the County property on which it is located. The Datran Center includes office, retail, and hotel uses and transit parking. The arrangement provides over $\$ 600,000$ in revenue to the County annually.

When a development project is proposed, it is reviewed by a county development commission, and zoning is created at the time of the permitting. Then it is reviewed by the individual municipality in which the development will be located. The County development commission is open to market needs. They would like to see the stations be an integral part of the development; however, they try to pick the best that is offered by any given set of proposals. No formal requirements apply to developers. However, transit-friendly plans get higher points and more favorable consideration.

Currently, the Rapid Transit Zone covers only the MetroRail system. It is believed that a transit overlay zone would work well for larger, permanent bus facilities where higher density is encouraged for attracting and facilitating land development. It may also simplify the development regulatory process for getting zoning approvals for transit facilities, such as park-and-ride lots. ${ }^{46}$

${ }^{46}$ Frank Talleda, Miami-Dade Transit, phone conversation, 9/26/01. 
The City of Pleasant Grove, Utah, located in between Salt Lake City and Provo, has established by ordinance a transit overlay zone. The Transit Overlay allows for a more intense and efficient use of land at increased densities for the mutual reinforcement of public investments and private development. In return, developers must conform projects to building standards in the Transit Overlay that are designed to create a safe and pleasant environment near transit stations oriented to pedestrians and to those who rely upon public transportation. The Transit Overlay only applies to a zoning district when a Regional Transit Center is included as part of any proposed development. A Regional Transit Center, as defined in the Transit Overlay ordinance, is a transportation complex that:

- must provide 150 park-and-ride parking spaces, or

- must participate with government agencies in the development of a county-wide plan to meet federal Environmental Protection Agency air quality standards, or

- must be used by at least three local bus routes or at least two express bus routes or has the potential to provide a light or commuter rail station. ${ }^{47}$

\section{Level of Service Mechanisms}

Methods for evaluating transportation level of service are undergoing significant changes in Florida. With such changes come new opportunities to enhance or develop mechanisms for engaging private sector participation in paying some portion of the costs of transit capital and operations. This discussion summarizes new directions under pursuit.

A major limitation of the transportation concurrency evaluation process in Florida, as it affects transit system development, has been the difficulty in assessing level of service equally across modes. Established measurement techniques and standards to compare modal options must be in place in order for a land developer to justify transit investments to satisfy transportation concurrency requirements.

In the transportation planning process, the private auto historically has been viewed as the primary mode of travel around which other modes are auxiliary or supportive at best. Regarding transportation concurrency, public transit is viewed as a motor vehicle trip reduction measure. Local governments in Florida can justify the use of transit service as a mitigating factor only if it can be proven that transit service will have the effect of shifting mode split and reducing motor vehicle trips to and from the development site, thereby maintaining established highway LOS standards.

\footnotetext{
${ }^{47}$ Pleasant Grove Code, Chap. 14.14, Transit Overlay.
} 
If local ordinances contain language requiring transit facilities as part of land development, the ordinances mostly specify bus shelters. According to the Transit Capacity and Quality of Service Manual, prepared by Kittelson \& Associates, bus shelters are an amenity, albeit an important one, but not a backbone characteristic of service that enables a person to use transit successfully. ${ }^{48}$

Roadway level of service does affect public bus transit service, since transit vehicles use the road system to deliver service. Contributions to road improvements do help transit; however, a high roadway level of service is not sufficient for transit to work properly. Transit systems require additional physical facilities and vehicles, and the funds to operate the system.

\section{Multi-Modal Level of Service Measures}

The Transportation and Land Use Study Committee (TLUSC), convened by the Governor in 1998, believed that pedestrian mobility with access to transit should be the primary focus of local governments if a real mode shift from private automobile to alternative modes is to be realized.

The TLUSC intended that multi-modal LOS measures should be used as incentives by local governments through the allowance of LOS trade-offs from private automobile mobility to other modes. Additionally, local governments should work with developers to reduce requirements for motor vehicle concurrency through providing facilities for transit and other modes. ${ }^{49}$ The use of multi-modal level of service measures were successfully recognized and incorporated into transportation concurrency law by the 1999 Florida Legislature.

Since then, the Florida Department of Transportation (FDOT) issued its 2002 edition of the Quality/Level of Service Handbook, which incorporates the leading evaluation techniques for transit and other modes. ${ }^{50}$

At this time, FDOT has discouraged the use of these techniques to quantify the value of trade-offs among modes. However, through further refinement of techniques, the multi-modal level of service measures have the potential to provide local governments

\footnotetext{
48 "Highlights of the Transit Capacity and Quality of Service Manual: First Edition," Transit Cooperative Research Program, Federal Transit Administration, Transportation Research Board, National Research Council, Washington, D.C., November 1999, Number 35, p. 27.

49 Sprinkle Consulting, Inc., "Assessing Level of Service Equally Across Modes," Prepared for FDOT Systems Planning Office, March 2001, p. 29.

50 The 2002 edition of the Quality/Level of Service Handbook can be found currently at http://www11.myflorida.com/planning/systems/sm/los/default.htm
} 
with the tools to quantify the value of these trade-offs in the future. ${ }^{51}$

The desire of FDOT has been to develop a comparable evaluative process for transit level of service, which would supposedly yield a similar local planning response to that received for highways. According to local planning processes, those road segments performing at a poor level of service generally receive priority for funding of improvements. The intent is that the application of the measurement of level of service for transit and subsequent establishment of transit LOS standards would shine a spotlight on those aspects of transit with low quality of service in order for them to receive higher prioritization for funding of improvements at the local level.

So far, transit agencies have been hesitant about the results of preliminary testing of these evaluative processes due to the perception that the local level response to any evidence of poor transit quality would be punitive rather than supportive. This may indicate that some local governments and their respective communities continue to prefer a highway-only transportation system.

Another concern is that the service development and priorities for each transit agency may differ so much from one to another that attempting to standardize the measurement of quality of service across all transit agencies does more to muddle rather than clarify the status of service quality. Clearly, developing measures for transit quality of service has proven to be a much more complex undertaking than developing level of service measures for roadways.

The Transit Capacity and Quality of Service Manual (TCQSM), prepared by Kittelson \& Associates, Inc., was developed as a transit companion to the Highway Capacity Manual. Based upon the TCQSM, the Florida MPO Transit QOS [Quality of Service] Evaluation, Agency Reporting Guide was subsequently prepared to provide guidance for transit agencies in using the methodology for measuring transit quality of service. The TCQSM proposes the use of transit availability measures and quality of service measures, from the passenger's point of view.

It is the traveler's experience that will determine whether he or she chooses to use transit service, thus shifting the mode split from private automobile travel to transit.

\footnotetext{
${ }^{51}$ Studies can be found on the FDOT Systems Planning web site listed in footnote \#50. These include multi-modal level of service analysis techniques at the planning level, multi-modal quality of service for transit and pedestrian modes of travel, multi-modal corridor level of service analysis, research involving assessing level of service equally across modes, and assessing multi-modal level of service over a facility based on the following facility definitions:

- $\quad$ an intersection, bus stop, or street crossing (point)

- a roadway between points or intersections (segment)

- a series of segments and intersections (facility)

- a group of parallel facilities (corridor)

- a community or entire area (areawide)
} 
This shift in mode split is what would justify the use of private sector land developer funds to pay the costs of transit facilities and operations improvements.

As a result, it would appear that those aspects of transit service that private sector land developer funding should go toward are the ones that would really make a difference in terms of ridership. Using the categories of performance measures above, Kittelson argues that availability of service first must be provided before quality of service can be considered. Availability includes such factors as:

- Service Coverage: Does bus transit serve my residential area? Does it serve the area to which I want to travel?

- Hours of Service: Is bus transit service provided during the times of day that I need to travel?

- Frequency: Are buses running frequently enough that I don't have to wait too long?

All these conditions must be met for bus service to be considered available. These conditions have entirely to do with bus operations. However, in most cases, if land developers are contributing funds for bus transit, the funds are usually earmarked for bus shelters or related amenities. Bus shelters are one of the few examples of a transit-related fixed capital facility that can be demonstrated to specifically serve a particular new development. As a result, developer funds go toward bus shelters, whether that is the most crucial need or not.

Further research for FDOT includes a study that investigated multi-modal level of service at various points in the traveler's journey. With respect to bus transit, the point of concern is the bus stop. Rather than physical amenities such as bus shelters, the primary service measure at the bus stop was identified to be the frequency of bus service at the bus stop. Stops that incorporate multiple routes enhance level of service by providing greater choice of destination.

Secondary service measures include pedestrian access to the bus stop, as described by the ease of street crossings to access the bus stop. These also include the presence of sidewalks adjacent to the bus stop, the distance of the bus stop from the trip origin or final destination and presence of obstacles as measured by the degree of ADA (the federal Americans With Disabilities Act) accessibility of the bus stop.

Other secondary measures include passenger loading as measured by the number of boarding passengers, and a comfort convenience measure that includes transit amenities at the bus stop. A transit amenities survey of RTS bus riders (Regional Transit System, City of Gainesville, Florida) was also conducted, which found that the presence of a bus shelter and bench were considered to be the most important bus 
stop amenities. ${ }^{52}$ The results of the survey cited above should inform local governments as to what are the most important bus transit amenities to negotiate as conditions of land development.

According to the primary need for available service, the most important bus transit service elements include funding for bus operations to the development site. Secondarily, it includes the more frequent placement of bus stops to serve the development, street design and traffic controls to aid pedestrian crossing, sidewalks, and Americans with Disabilities access.

Once local governments are able to incorporate multi-modal LOS techniques in transportation planning activities, then local governments will have the ability to establish acceptable LOS standards for transit service to satisfy concurrency. Once those standards are established, this can provide the basis for requesting the provision of transit facilities and/or operations funding as a part of the land development negotiation process. The emphasis should be on funding the primary service measures first, such as frequency of bus service.

\section{Broward County, Florida}

A proposed change to the fee assessment process in Broward County would replace the current roadway concurrency system, the road impact fee, and the transit impact fee with a transit-oriented concurrency system. The focus of a transit-oriented concurrency system would be to have proposed developments contributing a fair share towards transit improvements, as mitigation for transportation concurrency, instead of constructing or paying for roadway improvements. Legal, fiscal, and intergovernmental issues need to be resolved before the county can adopt this proposal. ${ }^{53}$

The proposal calls for the county to be divided into Transportation Concurrency Management Areas (TCMAs). Each TCMA could either use the new transit-oriented system or opt out of the program and use a conventional concurrency system. A developer would pay a fee into the Transit TCMA, proportionate to the transportation impact of the proposed development, which would contribute to the funding of the fiveyear transit development plan.

In order to change from a roadway improvement orientation to a transit enhancement orientation, the County Department of Planning \& Environmental Protection recommended that the County change both the basic standards used to measure

\footnotetext{
52 Dr. Linda B. Crider. "Multi-Modal LOS 'Point' Level of Service Project, Final Report" Department of Urban and Regional Planning, University of Florida, Gainesville, August, 2001, p. 55.

53 The description of the proposed alternative concurrency system is from information in the paper, "Creating a Transit-Oriented Concurrency System for Broward County-A Concept Paper." Broward County Department of Planning \& Environmental Protection. Broward County, Florida Development Management Division, May 2001.
} 
adequate transportation facilities and the type of mitigation implemented. By using the Transit Capacity and Quality of Service Manual (TCQSM), referenced above, the County would not only calculate the capacity of transit vehicles and facilities, but it would also measure the quality of transit service from the user's perspective. Specific criteria for assessing the quality of transit service includes service frequency, hours of service, service coverage, passenger loading (degree of crowding), reliability, and a comparison of transit versus auto travel time.

This proposed assessment, to satisfy transit-based concurrency, is envisioned as a "payand-go" system, meaning that the developer's only obligation is to pay the appropriate amount to the County. Under a "pay-and-go" system, the payment would be made at the site plan stage, when the specific nature of each development is well-defined. This would enable a more accurate calculation of the expected impact of each project, and eliminate the need for monitoring and enforcement.

Transportation concurrency exception areas (urban infill) and exemptions for de minimis impacts would be eliminated. Currently, Broward County's urban infill area comprises most of the eastern part of the county.

The adoption of this type of concurrency system would not, by itself, require additional public funding for transit. The transit service standards adopted by the County Commission for each TCMA would have to be based on a reasonable projection of revenues. Any increase in these standards above current service levels would have to be justified in terms of additional funding sources. Broward County's transit development plan (TDP) guides the capital and operations improvements of the transit system over the next five years. However, it does not contain revenue projections for the five-year period, and is not intended to match planned improvements to future revenues.

According to the proposal, for the TDP to be usable for the purposes of a transitoriented concurrency system, it would need to be based on projected revenues for the five-year period. The projection should include an estimate of revenue from the concurrency system, based on the portion of future transit demand which will be attributable to new development. The planned improvements in the TDP should be limited so that they are financially feasible based on the revenue projections. The type and distribution of improvements in the TDP would need to match the transit service standards that are being recommended for each TCMA.

The transit service standards would therefore be much more than a key factor in the concurrency system; they would be the policy guides to determine the location and type of enhancements for public sector expenditures on transit.

The general form of a fair share calculation would be: 


$\begin{aligned} & \text { Trip generation of } \\ & \text { proposed development }\end{aligned}$
x $\quad \begin{aligned} & \text { Cost/trip for TCMA projects } \\ & \text { in TDP (five years of cost). }\end{aligned}$

Several important assumptions are built into the sample formula above. First, it assesses all of a new development's trips as if they were transit trips. This is, of course, not a realistic assumption, but it could be a reasonable proxy based on the deletion of all roadway-related assessments (roadway concurrency and road impact fees).

A second assumption is that a cost per trip for the TDP can be estimated. This means that a projection of future transit ridership based on the planned improvements has been made. This projection may be made more difficult to the degree that unconventional enhancements are included in the TDP. There may also be difficulty splitting the costs of some improvements among the TCMAs. Finally, the formula implies that the TDP will be updated annually, so that there will always be five years of cost involved.

According to the proposal, there may also be a need to modify the formula to account for other transit revenues that will be paid by the occupants of new development during the five-year period. This avoidance of "double counting" has been used frequently in impact fee methodologies. Since the funds provided by a land developer would all be used for TDP projects in the appropriate TCMA, the developer would not need to study and propose particular improvements. Also, the use of the funds for implementation of projects in the TDP would satisfy the timing requirement of concurrency. This is the link between the completion of the transportation enhancement and the occupancy of the new development.

The proposal concludes with four recommended actions for Broward County:

- Initiate a general Comprehensive Plan amendment to the Transportation Element which would create a new policy consisting of the following: 1 ) divide the county into Transportation Concurrency Management Areas (TCMAs) as defined in Section 163.3180(7), FS; 2) utilize a quality of transit service concept as the transportation level of service standard for some or all of the TCMAs; 3 ) within those TCMAs which utilize a quality of transit service concept, require applicants for development approvals, as mitigation to satisfy transportation concurrency requirements, to make a fair share contribution towards the cost of implementing components of an adopted, financially feasible Transit Development Plan; and, 4) modify the timing of transportation concurrency assessment from the plat stage to the site plan stage, with a provision that no local government can issue a site plan approval without evidence from Broward County that the project has satisfied regional transportation concurrency requirements. 
- Request each municipality to indicate a TCMA preference.

- Request the MPO to recommend TCMAs and transit standards.

- Authorize hiring a consultant to review the second Comprehensive Plan.

\section{Pipelining}

Pipelining could be a method of payment by land developers that could be applied to public bus transit as well as to roadway facilities. The 1999 amendments to the concurrency law provide that land developers may pay a proportionate fair share contribution toward transportation facilities to serve the trips generated by a multiuse development of regional impact. ${ }^{54}$ Also referred to as pipelining, this method of payment for transportation facilities by land developers enables them to take the entire cost of the proportionate fair share mitigation for all affected road segments and put it toward the construction of just one or two of the needed segments. Under this approach, a critically needed road project could be put in place in its entirety.

What may be significant to bus transit is that the pipelining method of payment encourages developers to undertake large multi-use land development projects with a significant component of residential uses, which constitute the type of desirable development pattern that can achieve walkable communities with multiple transportation modes. ${ }^{55}$

The wording of the legislation in Chap. 163.3180(12)(e), F.S. states that the proportionate-share contribution may be applied to any transportation facility to satisfy the provisions of this subsection of the law. However, the law also provides a formula for the calculation of the proportionate-share contribution, based on the number of peak period trips reaching affected roadways. The formula as defined and provided, encourages the application of the pipelining mechanism to payments for roads only. Considering that the explicit intent of this legislation was to allow the development of DRIs "...designed to encourage pedestrian or other non-automotive modes of transportation...", ${ }^{56}$ the opportunity exists to develop a method for applying the pipelining mechanism to be used for bus transit facilities. It is recommended that the formula provided by law for calculating the proportionate share contribution, be reviewed in light of recent state-initiated efforts to develop multi-modal level of service measures. The goal would be to apply a proportionate share contribution based on bus passenger trips rather than on peak period motor vehicle trips.

\footnotetext{
${ }^{54}$ Chap. $163.3180(12)$, F.S.

${ }^{55}$ Final Report of the Transportation and Land Use Study Committee, January 15, 1999. Section 30 of CS/SB 2474 as enacted by the 1998 Florida Legislature.

${ }^{56}$ Chap. $163.3180(12)(b)$, F.S.
} 


\section{Impact Fees}

By the nature of impact fees, it is unlikely that there is much future potential for their use to provide funding for transit. As a regulatory device, impact fees are not supposed to raise too much revenue.

As provided in an earlier discussion about impact fees in this report, impact fees have almost exclusively been used for funding roadway improvements. Broward County is the only county with a transit impact fee. There is a proposal, as described above, to eliminate the transit impact fee and replace it with the proposed transit-oriented concurrency system.

In Hillsborough County, impact fees for transit can currently raise a small amount in places where fees are based upon current mode share. The existing transit mode share is on the order of 1-3 percent, as estimated by U.S. Census data. This data is collected based upon questions relating to the journey to work and no other trip purposes, so this gives a limited view of existing transit use. This method of determining funding for service development also locks the system into the existing mode split status quo. If transit service is funded to serve a three percent mode share, the service will likely be of a quality that will not attract anything higher than that.

There are a few new developments regarding impact fees that, while not having the effect of raising revenues for transit, instead may have positive indirect effects of encouraging development toward transit-friendly land use patterns. The Transportation Planning Bureau of Orlando recommended in 1998 that the road impact fee schedule be changed to a rate based upon Vehicle Miles of Travel (VMT) within designated transportation areas. Refinements are still being made to this proposal. If this change were implemented, the impact fees for urban infill development would be significantly reduced. This reduction in impact fees would attempt to redirect development as transit-oriented development into urban infill areas. The proposed VMT approach is simply a refinement of the roadway impact fee calculation. VMT would make the process more precise and allow the recognition of different land development patterns that are conducive to transit, such as multiple intersecting points within a development's street system. Furthermore, the City of Orlando has enacted an impact fee reduction ordinance that reduces roadway impact fees for developers in the Southeast Sector Plan if they provide amenities and facilities for transit users and construct development to promote the internal capture of trips.

The recent changes to the use of impact fees as legislatively enacted in 1999 through the creation of the multi-modal transportation district option, has had the effect of further reducing the effectiveness of impact fees to raise revenue for roadway improvements. The new legislation for multi-modal transportation districts includes the provision that "Local governments may reduce impact fees or local access fees for development within multimodal transportation districts based on the reduction of 
vehicle trips per household or vehicles miles of travel expected from the development pattern planned for the district.. ${ }^{157}$ The intended effect is to encourage developers to adopt development patterns as promoted by multi-modal transportation districts. While this will not raise funds for transit, it should have the positive effect of putting appropriate land development patterns in place that make bus transit more effective and efficient.

There may be a missed opportunity when impact fees are considered only for roadways and no other form of transportation. While there may be a reduction of vehicle trips per household, there will almost certainly still be a need for transportation, in one form or another. Broadening our view toward the development of a "transportation impact fee" might open new opportunities to fund transit using private sector land developer participation.

\section{Review Process for Developments of Regional Impact}

The Development of Regional Impact (DRI) review process focuses upon identifying impacts to the existing roadway system. DRIs are often located on large tracts of undeveloped land to which transit service has not yet extended. Developers will seek less costly undeveloped land, on the suburban fringe, where there is usually little or no transit service but is attractive because of market accessibility by the existing road system. As the suburb-to-suburb home-to-work travel pattern expands with increasing suburbanization, some transit agencies are withdrawing poorly used bus service extensions from new developments to downtowns in favor of focusing on service enhancements to existing well-used bus routes serving neighborhoods closer to the urban core.

Under the current DRI review process, level of transportation service is measured in terms of roadway capacity. Alternative transportation, such as ridesharing and transit, are identified as part of Transportation Systems Management (TSM) strategies for the purpose of mitigating development impacts on roadways rather than as a mode of transportation with its own level of service (LOS) standards. This necessarily leads to a determination of improvements, to be accomplished by the developer, which are intended to restore roadway LOS rather than improving use of transit as a mobility solution to the new development.

For example, the DRI Application for Development Approval (ADA) emphasizes and provides detailed instructions on quantifying the impacts to roadways as part of Question 21 - Transportation. At the end of Question 21, after parts A through $\mathrm{H}$ addressing quantifying roadway impacts have been addressed, there is the general question:

${ }^{57}$ Chap. 163.3180(15)(d), F.S. 
What provisions, including but not limited to sidewalks, bicycle paths, internal shuttles, ridesharing and public transit, will be made for the movement of people by means other than private automobile? Refer to internal design, site planning, parking provisions, location, etc.

Alternative modes are a procedural afterthought and it is implied that not much attention is expected by the developer to seriously consider other modes of transportation. All other modes, each having very different characteristics, are combined into one "other than automobile..." category for purposes of review. The Application for Development Approval provides further instructions:

The applicant must clearly document any estimate of mode split to transit or non-motorized transportation. The proposed usage should also be supported through an agreement with the transit agency and an acceptable internal roadway design...Change in mode split must be supported by the developer based on data collected on projects of similar intensity and use.

The burden of proof is placed upon the underdeveloped alternative mode, to demonstrate a shift in mode split. The new project is not likely to be permitted to set a precedent, if projects of similar intensity and use that demonstrate a higher transit mode share cannot be found.

Despite the limitations of the current Application for Development Approval, the DRI process has the potential to be an opportunity to guide DRIs in a positive direction toward State Comprehensive Plan goals for a truly balanced transportation system.

Developers must submit annual reports regarding the phased development of DRIs, which must identify modifications that are consistent with the plans and policies of the local host municipality, the Florida Department of Transportation, and the metropolitan planning organization. This places the responsibility upon these state and local agencies to have plans and policies that set the tone for improving transit. One way to accomplish this is for the provisions of Florida Administrative Code 9J-2.045 and the instructions for determining impacts as part of the ADA to be updated to include new methods for measuring multi-modal level of service. The F.A.C. guidance and ADA instructions should be updated as these methods are refined in the future by the Florida Department of Transportation.

Other hurdles in elevating the use of public transit improvements to address the transportation impacts of DRIs are:

- providing public bus transit improvements that can be demonstrated to specifically benefit the particular DRI contributing funds, and 
- demonstrating that those particular transit improvements cause a mode shift to transit.

Transportation improvements, as provided by developers, must meet certain tests as provided by state law. These tests are similar to those provided for impact fees, regardless of whether a local government has adopted an impact fee ordinance or not. These tests are that:

- The transportation need that must be mitigated must be attributable to the proposed development paying for the mitigation.

- The amount of the contribution must correspond to the amount needed to mitigate the impacts from the development.

- The funds must go toward improvements to serve that development.

- Developers of DRIs cannot be required to contribute funds for mitigation unless the host local government has an ordinance in place requiring non-DRIs to mitigate their impacts.

- Developers of DRIs cannot be charged twice to mitigate for the same impacts, as in the case that a local host government charges impact fees. ${ }^{58}$

These requirements pose special difficulties for developers to provide transit improvements as mitigation for the transportation impacts of a DRI. For example, if a high quality bus service, commensurate with highway level of service, is not in place, then it is not possible to reasonably estimate the need for transit service by a new development unless there is a way to measure latent demand for transit service. As a result, a very low number of bus trips is estimated. Consequently, a small amount of money or capital facilities is estimated to pay for bus mode share. Funds must be demonstrated to benefit the development. If there is an impact fee ordinance in place, then funds cannot go toward bus operations. This leaves capital facilities-bus shelters are the likely choice.

The Transit Capacity and Quality of Service Manual already assigns bus shelters as an amenity and not a necessary element of bus service availability. Bus shelters do not accomplish much if bus service is not available.

If funds can go toward operations, it is possible to quantify a cost of bus service to cover bus operations to serve those generated trips only; however, this still would not help if bus service does not yet extend out to the DRI. If effective bus transit service does not already exist in the area, then it is not possible to pay some incremental bus transit cost, commensurate with the number of new trips generated by a development, such that the new development benefits from the fees paid.

It is recommended that there to be some means to enable local governments to charge development for bus transit improvements that do not necessarily serve that

${ }^{58}$ Chapters 380.06(15)(d) and (e) and 380.06(16), F.S. 
development, but can be applied to bus routes that may be extended to serve the development in the future.

Whether the development is a DRI or not, the contribution should be consistent with the intent to provide transportation facilities concurrent with the impact of development and to maintain a transportation LOS, commensurate with the mobility demand generated by the development.

To reinforce the desired results of engaging land developers to pay for bus transit improvements as part of the DRI process, local governments should make full use of the planning and regulatory processes available to them to guide development toward locations where it is efficient to provide transit service.

These include:

- the long range transportation planning process and the transportation improvement plan of the MPO,

- the local government comprehensive planning process,

- urban development boundaries, and

- zoning and other tools within the land development code.

Additionally, local governments could provide disincentives for a development that is located outside the existing or planned service area of transit, while offering incentives that make it more desirable to build in areas within the existing and planned bus service area.

\section{Trip Reduction Ordinances}

Trip reduction ordinances are regulations passed by a local government, which require developers, property owners and employers to participate or assist in financing transportation management efforts. Ordinances may specify a target reduction in the number of vehicle trips expected from a development based on standardized trip generation rates. Ordinances may also establish peak periods for travel reduction, establish time tables for compliance, and penalties for non-compliance. ${ }^{59}$

In practice, trip reduction ordinances primarily enlist the participation of property owners and employers, but they can also target land developers. Transportation management efforts encompass a wide range of actions, including carpooling, telecommuting, and parking management but they also often include public transit

\footnotetext{
59 "Managing Our Way Through Congestion," Florida's Commute Alternatives System Handbook. Prepared for the Florida Department of Transportation, Public Transit Office. Prepared by the Center for Urban Transportation Research, University of South Florida, Tampa, May 1996.
} 
promotion. There is generally no limit to what activities are conducted, as long as those activities produce trip reduction results.

Trip reduction ordinances usually require employers or developers to submit plans that list the specific transportation demand management strategies to be employed and to survey commuters in order to quantify progress toward the goal of the ordinance. A local government could develop a trip reduction ordinance with requirements to identify and examine potential bus transit development efforts and implement them if they are deemed feasible as a means to mitigate traffic congestion.

Employers and developers can be penalized for not submitting a plan. Penalties for developers usually relate to the denial of a building permit.

Examples below describe how trip reduction ordinances have been used to engage land developers in improving transit service. There are no known trip reduction ordinances used by local governments in Florida; however, the City of Boca Raton has developed and is considering adopting a citywide trip reduction ordinance. The details are provided here.

\section{Boca Raton, Florida}

To meet the requirements of the Downtown Boca Raton DRI development order, the City of Boca Raton is required to prepare and implement a Transportation Demand Management (TDM) program before issuing certificates of occupancy for more than 1.5 million square feet of office equivalents. The City elected to prepare a trip reduction ordinance to meet this requirement, officially known as the Transportation Demand Management Plan.

The proposed ordinance would require the development of a TDM Plan for any building, structure, or development with a minimum of 50 full time and/or part time employees and has the specified minimum size: general retail of 15,000 square feet of gross floor area; general office of 50,000 square feet of gross floor area; medical office of 30,000 square feet of gross floor area; light industrial/warehouse of 100,000 square feet of gross floor area; and others including hotel/motels, schools, nursing homes, movie theatres, day care centers, restaurants, recreation facilities, and government or institutional uses.

The requirements of the TDM Plan would include provisions for facilities supporting a variety of alternative transportation modes, including transit. The TDM Plan for each development would adopt some combination of at least two elements contained in a list that includes: 
- public transit incentive programs, including the construction of transit shelters and amenities and the provision of fare subsidies;

- public transit improvements, such as changes in service routes; increases in frequency of service, alteration in the location of facilities; and the establishment of fare incentive programs and other measures designated to make public transit service more accessible to the occupants of the proposed use; and

- designated spaces provided on site that are restricted to bus pool vehicles, for those who utilize bus subscription service.

Bus pool spaces would be provided at a minimum rate of 2 percent of the total parking required by the City Code of Ordinances or the Downtown Development Order. The spaces must be non-handicapped employee parking spaces located closest to the building entrance. ${ }^{60}$

\section{Cambridge, Massachusetts}

Two mechanisms are used to encourage land developer participation in paying for transit capital and operating costs in Cambridge, Massachusetts. These are the Parking and Transportation Demand Management Ordinance (PTDM) and the Project Review/Traffic special permit in Cambridge's zoning code. PTDM (Chapter 10.18 of the Municipal Code) and Project Review (Article 19 of the Zoning Code) are independent ordinances. The goal of the City is to coordinate the implementation of the two ordinances in order to streamline the process for developers. ${ }^{61}$

Developers are required to engage in transportation demand management and/or transportation mitigation measures but are also able to customize their programs. When bus transit is included as a proposed measure in a development application, building and maintaining bus shelters is the main device used.

Zoning permits also can contain the requirement of providing shuttle services to rail hubs, sidewalks, and signage, in addition to bus shelters. Several projects that have received permits under PTDM or Project Review/Traffic are involved in funding a shuttle service from a commuter rail hub in Boston to employment centers in Cambridge. The businesses are required by their permits to fund an initial match to the City's start-up funding. In subsequent years, the businesses will bear the sole financial responsibility for the shuttle service. The shuttle service is a joint effort between the City and the Charles River Transportation Management Association. It will be operated by a private contractor and not by the Massachusetts Bay Transportation Authority, which operates bus, subway, light rail, and commuter rail systems.

\footnotetext{
${ }^{60}$ Proposed ordinance drafted by John Reilly, City of Boca Raton, May 21, 2001.

${ }^{61}$ Catherine Preston, PTDM Officer, City of Cambridge, email communication.
} 


\section{Pasadena, California}

The purpose of this trip reduction ordinance is to ensure that major nonresidential development projects accommodate facilities for alternative modes of transportation. For nonresidential development projects and the nonresidential portion of mixed-use development projects that exceed 100,000 square feet of gross floor area, the requirements include the following:

1. Bus stop improvements, including bus pullouts, bus pads and right-of-way for bus shelters are required as mitigation measures if a proposed development will have substantial traffic impacts.

2. A passenger loading area for carpool and vanpool vehicles must be provided on site. The area designated must be at a minimum of sufficient size to accommodate the number of waiting vehicles equivalent to 10 percent of the required number of carpool and vanpool spaces.

3. Connecting sidewalks must be provided between the external pedestrian system and each building in the development. ${ }^{62}$

\section{Franklin, Tennessee}

The City of Franklin is located south of Nashville and has a population of 41,000 . There is a proposed trip reduction ordinance still under review by City staff. The Transportation Management Association Group, authors of the draft ordinance, anticipates that interest in growth management will speed the adoption of the ordinance. The proposed ordinance includes a Developer Program that includes Tier 1 and Tier 2 actions. Tier 1 incorporates actions that have a modest cost and a modest impact on travel behavior, such as information display/kiosks and the encouragement of ridesharing. Tier 1 incentives are recognition and publicity.

Tier 2 actions are considered "highly effective" and include sidewalks, access for bus service, safe bus loading zones, bus shelters, land for transit facilities, and the operation of, or the financial contribution to, transit services (shuttles or express buses). The incentive for participation at this level would include road impact fee offsets, fast track approval of the development plan, parking requirement reduction, and increased floor area ratio. ${ }^{63}$

\section{Prince George's County, Maryland}

The Maryland National Capital Park and Planning Commission (MNCPPC) is currently responding to a request from the Prince George's County Council to create Transit

\footnotetext{
62 Pasadena Codes, Ord. 6573, 1993; Ord. 6172, 1986.

63 Draft Trip Reduction Ordinance, Franklin County, TN. Conversations with Diane Davidson, The TMA Group.
} 
District Development Plans (TDDP) in the College Park, Prince George's Plaza, New Carrollton, and West Hyattsville areas of the County. A transit district is a legally defined geographic area in which vehicle trip reduction procedures, strategies, and programs are required. Developers within transit districts may be asked to provide bus shelter installations, transit use incentives and improved pedestrian facilities. The goal of the TDM measures is to reduce vehicle trips during specified periods of the day. ${ }^{64}$

\section{Special Assessments}

Special Assessments are fees charged against property within a geographically defined district, to finance specific capital improvements or services. Special assessments are used more to pay for new improvements rather than their replacements. These districts can be used to provide public transportation.

While a special assessment district does not exclusively target private land developers, it does target owners of property within a specific area that is usually undergoing new development or redevelopment, and so is in need of new public facilities and services. Property owners of such land are also frequently land developers. Developers are often willing to pay to hasten placement of improvements necessary to increase land values.

Special assessments are a type of special financing district. Special financing districts are distinct geographic areas created by local governments, usually with the consent of property owners within the district, to raise funds, provide special services, and construct capital facilities within the district. These districts may lie wholly within a larger jurisdiction, or the boundaries of the special financing district may lie in more than one jurisdiction.

Special assessments are related to but different from tax increment financing, which is used as another type of special financing district. Special assessments are distinguished from tax increment financing (TIF) in that TIFs are dependent on the parent jurisdiction, whereas a special assessment district may be independent from the parent jurisdiction. In TIF districts, there are no additional fees charged to property owners, as are charged in special assessment districts. ${ }^{65}$ A discussion of tax increment financing is found in the previous section on "Current Approaches for Engaging Private Sector Involvement."

Special assessment districts are not independent or dependent special districts, which impose a tax. Special assessments impose a fee. This technique also can be used in addition to impact fees or other exactions imposed on land developers. Special assessments are distinguished from impact fees in that these districts can use public

\footnotetext{
${ }^{64}$ Communications with Betty Hager Francis, Director, Prince George's County Department of Public Works and Transportation and Karen Campbell, Prince George's Office of the County Council, Maryland.

${ }^{65}$ National Association of Homebuilders, Impact Fee Handbook, Homebuilder Press, Washington, D.C., 1997, p. 24.
} 
borrowing power rather than relying upon private borrowing power, which reduces financing costs. ${ }^{66}$

Property owners within a special assessment district also have a voice in the decisions regarding what facilities will be provided as a result of the assessment. However, there is the problem of majority rule in which a person may oppose adoption of a special assessment district that includes his/her property but is forced to participate in the payment of the project cost. Like an impact fee, the developer may also shift the costs to the final consumer.

The power to set up a special district must come by State legislation. Florida allows local governments to create special districts. Florida courts have addressed issues that distinguish between taxation and special assessments. In Collier County v. State of Florida, ${ }^{67}$ the Florida Supreme Court stated, "...local governments have no other authority to levy taxes, other than ad valorem taxes, except as provided by general law. The County does, however, possess authority to impose special assessments and user fees."

In another case, City of Boca Raton v. State of Florida, ${ }^{68}$ the court explained the difference between a tax and a special assessment.

A legally imposed special assessment is not a tax. Taxes and special assessments are distinguishable in that, while both are mandatory, there is no requirement that taxes provide any specific benefit to the property; instead, they may be levied throughout the particular taxing unit for the general benefit of residents and property. A tax is an enforced burden of contribution imposed by sovereign right for the support of the government, the administration of law, and to execute the various functions the sovereign is called on to perform.

On the other hand, special assessments must confer a specific benefit upon the land burdened by the assessment... A special assessment is like a tax in that it is an enforced contribution from the property owner; it may possess other points of similarity to a tax but it is inherently different and governed by entirely different principles. It is imposed upon the theory that that portion of the community that is required to bear it receives some special or peculiar benefit in the enhancement of value of the property against which it is imposed as a result of the improvement made with the proceeds of the special assessment. It is limited to the property benefited, is not governed by uniformity and may be determined legislatively or judicially.

\footnotetext{
${ }^{66}$ National Association of Homebuilders, Impact Fee Handbook, Homebuilder Press, Washington, D.C., 1997, p. 24.

${ }^{67}$ Collier County, Florida v. State of Florida (1999, FL) 733 So. 2d 1012.

${ }^{68}$ City of Boca Raton v. State (1992, FL) 595 So. 2d 25.
} 
As a result, the local government must conduct a study prior to instituting a special assessment, which verifies that the benefits received by those properties paying the assessment will enhance property value. This can be difficult to prove for local bus circulators. The use of special assessments may have future applications for use to support bus rapid transit.

While general ad valorem taxes vary from year to year and fluctuate in proportion to changes in the assessed valuation, a special assessment is customarily a fixed amount and is often payable in annual installments, until the project is completely paid off. The installment amount is usually fixed at the time of the initial levy and does not fluctuate as a result of changes in ad valorem valuation or increases in the cost of maintaining the improvement. ${ }^{69}$

Provisions in the Florida Constitution and the Florida Statutes that afford taxpayers the ability to challenge state taxes do not apply to special assessments since they are not considered to be taxes. ${ }^{70}$ The validity of a special assessment depends on the benefit received by the recipients of the service or improvement, whether the recipients are spread throughout the entire community or are merely located in a limited specified area within the community. ${ }^{71}$

Special assessments may also be called service charges or user fees. The Florida Supreme Court has also defined user fees as "...fees [that] are charged in exchange for a particular governmental service which benefits the party paying the fee in a manner not shared by other members of society. ${ }^{172}$ Therefore, user fees are similar to special assessments, because the fee "must result in a benefit not shared by persons not required to pay the fee. ${ }^{\prime \prime 3}$

Special assessments are often administered through special taxing districts or municipal service benefit units. Chap. 125.01(1)(q), F.S. authorizes a county that provides municipal services, to establish a municipal services taxing unit (MSTU) or a municipal services benefit unit (MSBU), which is a means to raise revenues from those properties within a specific geographic area that will benefit from the service. The difference between a MSTU and a MSBU is that MSBUs raise revenues through service charges or special assessments rather than taxes.

A MSBU is not a dependent special district. A MSBU must be created by ordinance of the governing body of the affected municipality, the consent of which is granted annually for a term of years. The boundaries of the MSBU may include all or part of the boundaries of a municipality. The law specifies that a MSBU can be created for the

69 State v. Halifax Hospital Dist. (1963, FL) 159 So. 2d 231.

70 Zipperer v. City of Fort Myers (1995, $11^{\text {th }}$ Cir) 41 F.3d 619.

71 Sarasota County v. Sarasota Church of Christ (1995, FL) 667 So. 2d 180

72 State v. City of Port Orange (1994, FL) 650 So. 2d 1.

${ }^{73}$ Collier County, Florida v. State of Florida (1999, FL) 733 So. 2d 1012. 
purpose of providing transportation.

Projects involving the use of special assessments tend to be used most often for smaller, localized projects. They can be applied to finance general public improvements in a local district where the whole district has benefited, although not necessarily uniformly. These districts typically require that a portion of the cost of the project be allocated to the municipality at large and paid from general revenue sources. After the public benefits are allocated, the remaining costs are paid by those who receive private benefits. The allocation to specific parcels may be calculated using simple formulas or may require professional appraisals.

Special assessments provide an alternative to negotiating with developers to secure financing for new improvements. Financing through special assessments avoids some of the legal restrictions on local taxation and borrowing. This may be more politically acceptable to taxpayers than are other sources of revenue. Special assessments expedite the placement of infrastructure, which lowers long term costs of construction. They work best where long repayment periods are not needed, just in case there is an economic downturn.

\section{San Francisco, California}

San Francisco provides an example of a special assessment district used to provide public transportation purposes, although the name of the ordinance creating the special assessment district can be deceiving. The Transit Impact Development Fee Ordinance, adopted in 1981, enables San Francisco County and City to charge a one-time fee to developers of office properties within a special assessment district in downtown San Francisco. The funds raised go to the San Francisco Municipal Railway's operating revenue fund. The fee covers the cost of providing transit services over the 45 -year life of an office building with the maximum fee per gross square foot set at $\$ 5.00 .^{74}$

${ }^{74}$ Funding Strategies for Public Transportation, Volume 2 Casebook, TCRP Report 31, 1998. 


\section{Recommendations}

The following recommendations are listed below to summarize those main points made in earlier sections of this report. They are offered to assist local governments and transit agencies in maximizing their options in engaging private sector land developer participation in contributing toward bus transit capital facilities and operations costs.

1. Begin with a well-crafted local government comprehensive plan (LGCP) with strong and clear policies regarding transit-friendly land development patterns. The LGCP and the transit development plan (TDP) should support and reinforce each other so that land development and redevelopment occur where public bus transit is able to efficiently provide high quality service. (See pp. 4-5 and p.

\section{Also see p. 28, Miami-Dade example.)}

2. If not already accomplished, consider the adoption of an urban services boundary as well as the designation of transit service corridors, which focus both public and private resources for enhancing bus service along roadways that are served by existing and planned bus routes. (See p. 4 and p. 14. See also p.

\section{8, Miami-Dade example.)}

3. Maintain an up-to-date land development code (LDC), consistent with the intent of the LGCP. A good LDC strikes the right balance between providing predictability and flexibility to the land development process. (See p. 14.)

4. Consider the use of conditional (p. 18), incentive (p. 16), and overlay zoning (pp. 51-53) for purposes of securing private sector contributions to public bus transit. (See pp. 16-22.)

5. Develop guidance manuals for use by the host local government and the private land developer, regarding preferred development design concepts to enhance transit mobility and transit amenities for customers. It is far easier for a developer to provide what the community would ultimately like to have if models and examples are available. (See pp. 18-19.)

6. Using the transit level of service (LOS) measures developed by FDOT, establish transit LOS standards and provide these as the basis for requesting the provision of transit facilities and/or operations funding as a part of the land development negotiation process. (See pp. 54-57.)

7. Prioritize those elements most needed for the bus system, for which private sector land developers would be asked to provide. This would first prioritize the elements of bus service availability, such as frequency and duration of bus 
service to and from the development site, then secondarily upon bus service quality, such as customer amenities. (See pp. 56-57.)

8. As it relates to any land development, large or small, establish a means to enable local governments to charge development for bus transit improvements that do not necessarily serve that development but go toward bus service development of routes that may be extended to serve that development in the future. (See p. 63, beginning with "Other hurdles...," through p. 65.)

9. As part of the provisions of Florida Administrative Code 9J-2.045 as well as the instructions for determining impacts in the DRI Application for Development Approval, incorporate the directive to use multi-modal level of service measures. (See pp. 62-63.)

10. The 1999 amendments to the concurrency law provide that land developers may pay a proportionate fair share contribution toward transportation facilities to serve the trips generated by a multiuse development of regional impact. It is recommended that the formula provided by law for calculating the proportionate share contribution, be reviewed in light of recent state-initiated efforts to develop multi-modal level of service measures. The goal would be to apply a proportionate share contribution based on bus passenger trips rather than on peak period motor vehicle trips. (See p. 60.)

11. Consider the adoption of other regulatory approaches, such as trip reduction ordinances (pp. 65-69) and special financing districts (See pp. 15-16 regarding tax increment financing and pp. 69-72 regarding special assessments), to provide for public bus transit operations and capital facilities.

12. Consider offering incentive programs to land developers, such as those that offer density bonuses, lower parking requirements and expedited permitting advantages, in return for transit improvements. (See p. 11.)

13. Invest in professional development opportunities for local government staff to become more informed about the economics of land development and to enhance negotiation skills. (See p. 7, last paragraph starting with "A wellcrafted land development code...." Also see pp. 10, 13, and 15, first paragraph.

14. Review the application processes for low-income housing programs to determine how transit services and facilities can be incorporated and prioritized as valued features in application proposals. Such features would cause land developers who propose them to score higher in the rating process. (See pp. 49-51.) 
15. Consider using both regulatory and non-regulatory tools in combination. For example, special assessments can be used in combination with exactions. (See p. 69.)

16. Use various approaches to educating citizens about the value of public transit so that it becomes incorporated into the ethos of the community. High quality public bus transit would become the desire and expectation of the community. Such approaches might include establishing transportation management associations with neighborhood association participation, conducting social marketing campaigns, supporting public relations and outreach efforts of the public transit agency, and involving high school students in campaigns to promote alternative transportation. (See p. 48.)

This report has documented the known non-regulatory and regulatory tools, using illustrative case studies, which have been used to engage land developers in contributing toward public bus transit facilities and operations. This report also contains information about mechanisms that have rarely been but can be used by Florida localities, as well as recommendations for actions to improve those opportunities to enlist support for transit through the land development process. Finally, and notwithstanding the local government comprehensive planning process, the land development code, and the use of incentive programs, these are no substitutes for a local host government whose professional staff and executive leadership are allies and advocates for public bus transit and are committed to making public bus transit a priority in land development negotiations. 


\section{Appendix A Port Orange Comprehensive Plan}

Appendix A - 1 


\section{Appendix A. Port Orange Comprehensive Plan}

Objective 2.2 from the Port Orange Comprehensive Plan - Update '98 is included here, as an example of a well-written planning policy that can provide a foundation for a strong local land development code. Strong local government comprehensive plans and land development codes establish the authority of a local government to engage private sector land developer contributions toward public transit facilities and operations.

Objective 2.2: The City shall work with and continue to encourage VOTRAN to provide a safe and efficient mass transit system to the citizens of Port Orange at an acceptable level of service. Mass transit service shall be based upon the location of trip generators and attractors, and appropriate land uses. The City shall work with VOTRAN to achieve a 5 percent modal split for transit use by the year 2005.

Policy 2.2.1: The City shall designate all roads serviced by existing and/or proposed VOTRAN bus routes as "public transportation corridors."

Policy 2.2.2: The City shall ensure that all roads within designated transit corridors function at a level of service (LOS) sufficient to support the VOTRAN minimum local bus system. The peak hour directional LOS standard for transit shall be defined as the LOS standard for each particular roadway segment along a given transit route.

Policy 2.2.3: The city shall support the operational LOS performance standards for fixed-route transit systems as provided by the MPO in its 2020 Transportation Plan Update.

Policy 2.2.4: The city shall encourage land uses and site developments (both generators and attractors) which promote mass transit within designated public transportation corridors, with priority given to those projects that will bring the greatest increase in transit ridership.

Policy 2.2.5: The City shall guide the placement, type, and density of new development along public transportation corridors, in a manner consistent with the Future Land Use Element, so as to achieve the level of ridership needed to support mass transit.

Policy 2.2.6: Major trip generators and attractors, including new commercial developments exceeding 50,000 square feet in gross leasable space and new residential developments of more than 200 dwelling units, shall provide on-site space for bus stops if located on a public transportation corridor. 
Policy 2.2.7: The City shall continue to inform VOTRAN as to the proposed location of new transit generators and attractors as they are being reviewed.

Policy 2.2.8: The City shall require major trip generators and attractors (as defined by Policy 2.2.7 above) located on a public transportation corridor to incorporate elements of "transit-friendly design." Specific elements shall meet with VOTRAN's approval, and may include...

A. Transit stops meeting ADA requirements;

B. Parking lots and intersections designed with minimum corner turning radii for buses;

C. Clearly delineated walkways from the building to the transit stop; and

D. Buildings and transit stops placed close to the street.

Policy 2.2.9: By the year 2005, the City shall assess the feasibility of requiring a maximum (as opposed to a minimum) number of parking spaces for new developments along public transportation corridors.

Policy 2.2.10: The City shall work with VOTRAN to improve existing bus stops by refitting them with benches, clearly marked signs, lights, and covered or enclosed waiting areas. All bus stops shall be safe, convenient, and meet the needs of "transportation disadvantaged." 


\section{Appendix B Literature Review}

Appendix B - 1 


\section{Appendix B. Literature Review}

An annotated bibliography is provided here as a result of a search of the general literature in transportation research to determine how private sector participation or private sector land developer participation in providing transit facilities or operations has been addressed. This bibliography provides a representative selection of current sources that most closely address the topic of this report.

The literature review was conducted by researching professional and academic journals, periodicals, newspapers, textbooks, and other sources, including the Transportation Research Information Services (TRIS). Research and reports from allied professional associations, the University of South Florida (USF) LexisNexis Academic Universe and the USF General Business File ASAP were also used.

\section{Beimborn, Edward, Harvey Rabinowitz, and Peter Gugliotta, "Implementation Issues for Transit Sensitive Suburban Land Use Design." World Conference on Transportation Research, Sydney, Australia, July 1995.}

This paper examines guidelines that can be used to create situations in which transit, pedestrian, and bicycle facilities are used as a basis for land use design. The authors discuss reasons why it has been difficult in the past to incorporate public transit service into suburban areas in the United States. In order to implement transit sensitive land use techniques, an assessment of the user groups is necessary. User groups are identified as developers, local government staff and the market itself. Beimborn et al. view developers as a group who are "very open to change and will quickly adapt to new ideas." Developers, as well as those who finance development, must be willing to take risks, especially the risks involved with innovative approaches to transit funding. Since developers are motivated by the bottom line and are "highly market driven," successful projects are often emulated.

The problem that the authors perceive with developers, and others in the user groups, concerning transit issues is a "lack of knowledge" about transit. They think of transit in a negative way. "Most cannot conceive of using transit for their basic travel. There is a lack of knowledge of the basics of good pedestrian access and how to provide good connections from buildings to transit service. Further, there are few champions of the idea and a hesitancy to be early adopters of the concept." 
Suggestions for improving the chances of implementation of transit sensitive suburban land use design and acceptance by developers include the following.

- Increase awareness of transit service design by informing developers (and government personnel) of how transit is operated, the economics of transit, and the physical factors in transit route location.

- Conduct market research to identify market segments that may be attracted to live and work in transit based communities. In order to obtain investment commitments, a clearly demonstrated market potential must be demonstrated.

- Provide for transit-sensitive review of site plans and development proposals, either by a staff person with training in the transit service field, or by the transit agency if such a person is not on staff.

- Provide a transit checklist for potential developers that could be used informally to give developers information about which issues a municipality will consider when reviewing a proposal.

- Explore public/private opportunities for transit stop joint development. "A most opportune location for joint development by the private and public sectors is at transit stops. Local governments should consider a proactive approach to development surrounding stops. Large stops can become part of the surrounding buildings. Developers may pay to construct sheltered stop areas that tie directly to their buildings and revert the actual right-of-way to the municipality. The main benefit for the developer is the increased patronage that will flow from the transit stop directly into the building. For the municipality, capital costs are reduced. At smaller stops, simple retail services can become part of joint development efforts. The presence of retail services at transit stops can be contracted out to businesses for different services. This also allows small businesses to become established in each neighborhood. Another alternative is to seek joint development opportunities with private companies. In return for providing some of the needed funds to develop the transit stop, a private firm is allowed to use the adjacent land for retail service provision."

Buffkin, Tom, Roanne M. Neuwirth, and Marilyn Remer. "Institutional Issues: Public-Private Partnerships and the Minnesota Guidestar Travlink Operational Test." Intelligent Transportation: Realizing the Benefits. Proceedings of the 1996 Annual Meeting of ITS America, Houston, Texas, April 15-18, 1996.

Although the authors discuss one specific Intelligent Transportation Systems (ITS) project, the evaluation centered on key issues and lessons learned with the 
partnership process. Key issues include the formulation of the partnership process; the expectations of the participants; legal issues and other issues and stumbling blocks; what participants liked most and least; how much time participants spent on the partnerships; what participants would change about the process; comparison of the public/private partnership process with the traditional Request for Proposal (RFP) process; and advice for those undertaking a public/private partnership.

The authors determine that the major difficulties with carrying out the agreements are legal issues. These include proprietary issues and property rights; copyright and ownership; license agreements; confidentiality; and ability to carry out partnership agreements under the state's enabling legislation.

\section{"FTA's Innovative Financing Handbook," Federal Transit Administration, U.S. Department of Transportation, May 1995, currently found at http://www/fta/dpt/gov/library/monev/inovhnbk.html}

This work gives examples of innovative financing approaches that are available under the Federal Transit Act (Title 49 of the United States Code, Chapter 53). Specifically, ISTEA (1991) and Executive Order 12893 (1994) called for "more efficient management and enhancement of our Nation's public transit infrastructure through the creation of public/private investment partnerships." The Transportation Equity Act for the $21^{\text {st }}$ Century (TEA-21) continues these changes in traditional funding approaches. The handbook discusses several techniques that transit operators can use.

- Joint development of transit assets-Capital Program funds can be used for a variety of joint development activities, as long as they are physically or functionally related to a transit project and they enhance the effectiveness of the transit project. If the joint development relates to transit supportive development in FTA's "Livable Communities Initiative", FTA allows a great deal of flexibility in funding.

- Super turnkey and private financing also called Build/Operate/Transfer (BOT)-The "Super Turnkey" process which was authorized in Section 3019 of the Intermodal Surface Transportation Efficiency Act of 1991 (ISTEA) is one where the project engineers or project management consortium undertake to build, operate for a time, and transfer a facility to the purchaser. Purchasing, deliveries, and scheduling are directed by the Turnkey Manager. As a result, construction delays, start-up difficulties, disagreements about change orders and project timing are minimized, resulting in lower project costs and reduced litigation. 
- Toll revenue credits-ISTEA provides that toll revenues on public roads and bridges expended for capital investment may count as local match for Federal grant funds in a specific year. Since different modes of transportation are interconnected, capital expenditures to reduce congestion in a particular corridor benefit all modes in that corridor including automobiles, transit buses, and rail systems.

\section{"Funding Strategies for Public Transportation-Casebook," TCRP Report 31, Volume 2, Transportation Research Board: Washington, D.C., 1998.}

This report presents case studies on creative methods for generating revenue for public transportation capital and operating costs. It identifies external funding sources, such as dedicated taxes and transit impact fees. Agency-generated funds are also examined and include turnkey procurement, public-private partnerships, and joint development. Each case study includes lessons learned and contact information.

\section{"Growing Smart Legislative Guidebook: Model Statutes for Planning and the Management of Change," American Planning Association, 2002 Edition, currently found at http://www.planning.org/Guidebook/View.asp}

Incentive zoning is a technique that grants incentives or bonuses to developers on condition that certain physical, social, or cultural benefits or amenities are provided for the community. Bonuses are usually in the form of added permissible density to a development project. Waivers of regulatory requirements or fees are also used. Community benefits include transit access.

Hedley, Jason, "Using the Private Sector in the Implementation of ITS: A Look at Public/Private Partnerships," Intelligent Transportation: Realizing the Benefits. Proceedings of the 1996 Annual Meeting of ITS America. Houston, Texas, April 15-18, 1996.

While the author focuses on Intelligent Transportation Systems affordability, he also makes several important points concerning the motives for private sector involvement in public/private partnerships, as well as the risks for the private sector investor. He states that the private sector stands to gain more prestige and recognition as a provider of a service or set of services to the public. The private company may need to utilize data collected using government owned equipment and facilities. The government may decide to allow this data to be used only by companies that would be willing to enter into agreements with the 
public sector agency to reflect a public benefit from providing the information. Private firms may create income by selling a system or through value added resources that would provide a percentage to the public sector for providing the raw data resources.

Public sector barriers such as lack of enabling legislation and a lack of dialogue with private entities regarding partnerships increase private sector risks involving time and money. Other examples of risks that the author cites are stringent regulations, especially regarding right-of-way, and the lack of public commitment to a project.

Hinebaugh, Dennis, Laurel Land, and Lisa Staes. "Public Transit Access to Private Property," Center for Urban Transportation Research, August 2000.

This report, completed for the Florida Department of Transportation, examines the issues surrounding the legal rights of public transit agencies to enter and serve private property. A written survey was conducted of public transit operators to identify agency experiences, both positive and negative, related to their bus systems' access to private property. A written survey was also conducted of private property developers, owners, and managers. The purpose of this survey was to identify major concerns related to allowing direct vehicle access to public transit providers.

\section{"Innovative Financing: Evaluation of Pricing Options and Alternative Financing Mechanisms," Department of City Planning, City of New York, Transportation Division. August 1999.}

This report is an examination of current innovative transportation and transit funding approaches used across the United States. Financing tools are broken down into three categories: revenue raising, borrowing, and cost cutting.

Private participation revenue raising tools that could apply to bus transit operations include the following.

- Advertising revenue-In 1998, the transit agency in Orlando, FL (LYNX) had 70 of its 250 buses wrapped entirely in advertisements. Called "shrink wrap", this approach can generate substantial revenue. Generally, production costs vary for whole bus wraps and painting vary. The advertiser pays for the $\$ 8,000$ to $\$ 10,000$ wrapping, removal, and repainting in addition to the monthly ad fee. The rate for a whole bus wrap varies from $\$ 1,500$ per month, with a 6 -month minimum guarantee 
in a small media market to $\$ 6,500$ per month for one bus in a major media market.

- Air rights-Properties owned by transit agencies which have unused air rights may be sold to private entities for development subject to zoning restrictions.

- Joint development/facility connection fees-This approach involves the leasing of agency land to developers, who pay rent to the transit provider and develop the land. Fees can also be collected from a landowner or private tenant to physically connect their facility, usually an office building or retail establishment to a transit station or park-and-ride via a passageway.

- Leasing rights-of-way-Transit operators lease the space within their transportation corridors to telecommunications or other companies that use the area to install cabling or utility connections.

- Station concessions-Leasing concession stands on transit property provides steady income as well as additional amenities and convenience to those using the transportation system.

- Transit impact fees-This fee is charged to businesses in specific areas that would stand to benefit most from the new or improved service brought about by a specific transit improvement.

\section{Markus, Henry S., 1998. "1992-1997 Westside Light Rail Station Area Design, Planning \& Development Program-Accomplishments and Lessons Learned," Rail-Volution '98, September 12-16, 1998.}

One mechanism that governments and transit agencies are using to encourage private funding of transit facilities/operations is transit-oriented development. There are many references in the general literature to this subject.

This paper details the methods used to set up and successfully utilize a TOD project that included a rail station and bus service. The author recommends that public officials make standards clear and objective. For example, language should be specific: use "shall", not "may"; adopt "standards", not "guidelines". Markus states: "Mixed use TODs are the most effective type of development for reducing external automobile trips but are difficult to do. Public incentives are necessary. Mixed use projects can be vertical...or horizontal...Nationally, there is growing experience with mixed use urban villages (neo-traditional development). Combined with transit, this is a powerful and workable marketing concept." One important aspect the author addresses is public/private partnerships. He advises transit agencies to partner with local government, major property owners and developers. "Offer to split the cost of master planning but require a $50 \%$ private match. Be willing to modify transit facility location and design to take maximum advantage of major development projects. Define roles and responsibilities, and 
set clear joint objectives at the beginning for land uses, density, parking, block size, incentives, street connectivity, public involvement and so on. Either jointly hire a consulting team or create two teams, one for the private participants and another for the public. Use a charrette process with the decision makers and consultants in face to face discussion."

\section{"Summary of Provisions of RCW 47.46," (amended in 1995 and 1996), the State of Washington, currently found at http://ltc.leg.wa.gov/manual97/resou221.htm}

The legislative intent of this law is to allow the Department of Transportation to test the feasibility of building privately funded transportation systems and facilities through the use of innovative agreements with the private sector. Therefore, WSDOT is encouraged to take advantage of new opportunities provided by federal legislation that allow federal funds and programs to encourage private financing of transportation capital improvements. The DOT should enter into public private agreements for the private financing of these transportation capital improvements.

\section{"Transit Oriented Development-Creating Accessible and Multi-Modal Neighborhoods," TDM Encyclopedia, Victoria Transport Policy Institute, currently found at http://www.vtpi.org/tdm/tdm45.htm}

As noted above, the subject of transit-oriented development has received much attention in the transportation literature reviewed. A good description of what TOD is and how it can be implemented can be found in this encyclopedia, along with case studies and resources for additional information.

\section{Volinski, Joel, "Lessons Learned in Transit Efficiencies, Revenue Generation, and Cost Reduction," Center for Urban Transportation Research, University of South Florida, Tampa, Florida, June 1997.}

This report examines ways in which transit agencies are generating revenue or reducing costs through five methods, one of which is public/private partnerships. The author summarizes the lessons learned about partnerships that were provided in the survey responses of 75 public transit agencies.

- Hospitals, malls, universities, employers, tourist attractions, etc. have typically initiated partnerships with transit agencies. Transit systems should promote their interest in partnering and stay in touch with the needs of the broader community. 
- Transit is all about linkages, not just for getting people from point $A$ to point $B$, but linking public transit with community goals...those linkages should be positively exploited.

- If local share for capital projects can be obtained from other public or private partners, the transit agency can use their own limited resources for other capital or operating needs.

- Decentralize and customize transit services to local needs with the help of local sponsors.

- Maintain close ties with agencies that have complementary community improvement goals, such as Air Quality Districts, state EPAs, Downtown Development Authorities, Councils of Government, and MPOs.

- Use a colorful marketing approach to advertise for partners. Avoid bureaucratic language that emphasizes process and constraints. Talk about opportunities. Be extremely responsive to expressions of interest. Be flexible in negotiations.

- Many entities see public transportation in a positive light. If transit agencies develop strong partnerships with these, they can save money while also increasing ridership and revenue.

\section{McNamara, Bob, "Development Impact Fees: A Role for State Enabling Legislation," National Association of Home Builders, currently found at http://www.nahb.net/growth issues/fees\&taxes/growth impact.html}

This paper examines issues of fairness and legal sufficiency pertaining to the calculation and administration of impact fees. The author reviewed forty-six local impact fee ordinances in the United States, and concludes that state enabling legislation may help to reduce errors in areas that are prone to legal challenges by establishing uniform requirements and guidelines.

\section{Morris, Marya, "Creating Transit-Supportive Land-Use Regulations," Planning Advisory Service, Report Number 468, American Planning Association, December, 1996.}

This report presents examples of code provisions, standards, and guidelines that offer creative implementation strategies to encourage transit, pedestrian, and bicycle travel. The ordinances come from many states and address a variety of community situations. 


\section{"The Principles of Smart Development," Planning Advisory Service, Report Number 479, American Planning Association, Chicago, September 1998.}

Smart development incorporates the following principles: conserve valuable land, energy, and facilities resources; offer people multiple convenient transportation options; relieve traffic congestion and air pollution; offer residents a variety of dwelling choices; and, create attractive community-oriented neighborhoods. The sixth principle is implementation, which is the key to success.

The report states that since regulatory and financing systems primarily serve single-use, conventional, and suburban development patterns and designs, builders often stick with this model, choosing what the existing system encourages rather than spending time and money trying to overcome barriers to smart development. These barriers include local regulations (codes, standards, and processes) that act as obstacles to smart development. Lack of flexibility in subdivision and zoning codes discourages smart development with its smaller lots, higher densities, mixed uses, narrower streets, and emphasis on providing a range of transportation options. Needed variances for smart projects can lead to costly delays. Other barriers to smart development are market conditions, development and process costs, financing, and community involvement. A specific obstacle to bus transit is the fact that communities fail to recognize that increasing density within a quarter-mile of a transit stop also increases the likelihood of people walking to use transit.

In order to encourage transit-supportive development, or transit-oriented development, municipalities should mandate transit-oriented development along transit corridors through the establishment of overlay zones and revised street standards including internal connectivity standards.

\section{"Transit-Friendly Streets: Design and Traffic Management Strategies to Support Livable Communities," TCRP Report 33, Transportation Research Board, Washington, D.C., 1998.}

This report states that transit-friendly streets make transit use more efficient and convenient while making the street less convenient for automobiles while still accommodating them. Transit-friendly streets accomplish four goals: establish a clear priority for transit vehicle operations with convenient, accessible transit stops; reduce conflicts between cars and other vehicles, including reduction of vehicle speed; create a strong pedestrian orientation; and, are a part of larger community development or livability enhancing strategies. Several strategies for 
accomplishing this are discussed including creating priority lanes for transit vehicles and providing amenities for pedestrians and transit riders.

\section{"Transit-Oriented Tax Exemption," City of Gresham, Oregon, currently found at http://www.ci.gresham.or.us/departments/cedd/bap/infoandincentives/TOTE.htm}

The city's web site explains that the transit-oriented tax exemption (TOTE) is a targeted development incentive that grants limited, ten-year property tax exemptions for qualifying new transit-oriented developments in certain areas of the city. 